OPEN ACCESS

Edited by:

Zhiyong Shao,

Fudan University, China

Reviewed by:

Khursheed A. Wani,

University of Massachusetts Chan

Medical School, United States

Rui Xiao,

University of Florida, United States

*Correspondence:

Kavita Babu

kavita.babu@babulab.org;

kavitababu@babulab.in

${ }^{t}$ These authors have contributed

equally to this work

Specialty section:

This article was submitted to Molecular Signalling and Pathways, a section of the journal

Frontiers in Molecular Neuroscience

Received: 30 September 2021

Accepted: 11 November 2021

Published: 02 December 2021

Citation:

Bhat US, Shahi N, Surendran S and Babu K (2021) Neuropeptides and Behaviors: How Small Peptides Regulate Nervous System Function

and Behavioral Outputs.

Front. Mol. Neurosci. 14:786471. doi: 10.3389/fnmol.2021.786471

\section{Neuropeptides and Behaviors: How Small Peptides Regulate Nervous System Function and Behavioral Outputs}

\author{
Umer Saleem Bhat ${ }^{1,2 t}$, Navneet Shahi' ${ }^{1+}$, Siju Surendran ${ }^{1 \dagger}$ and Kavita Babu ${ }^{1 *}$ \\ ${ }^{1}$ Centre for Neuroscience, Indian Institute of Science, Bengaluru, India, ${ }^{2}$ Department of Biological Sciences, Indian Institute \\ of Science Education and Research, Mohali, India
}

One of the reasons that most multicellular animals survive and thrive is because of the adaptable and plastic nature of their nervous systems. For an organism to survive, it is essential for the animal to respond and adapt to environmental changes. This is achieved by sensing external cues and translating them into behaviors through changes in synaptic activity. The nervous system plays a crucial role in constantly evaluating environmental cues and allowing for behavioral plasticity in the organism. Multiple neurotransmitters and neuropeptides have been implicated as key players for integrating sensory information to produce the desired output. Because of its simple nervous system and well-established neuronal connectome, C. elegans acts as an excellent model to understand the mechanisms underlying behavioral plasticity. Here, we critically review how neuropeptides modulate a wide range of behaviors by allowing for changes in neuronal and synaptic signaling. This review will have a specific focus on feeding, mating, sleep, addiction, learning and locomotory behaviors in C. elegans. With a view to understand evolutionary relationships, we explore the functions and associated pathophysiology of $C$. elegans neuropeptides that are conserved across different phyla. Further, we discuss the mechanisms of neuropeptidergic signaling and how these signals are regulated in different behaviors. Finally, we attempt to provide insight into developing potential therapeutics for neuropeptide-related disorders.

Keywords: neuropeptides, C. elegans, locomotion, behavior, signaling

\section{INTRODUCTION}

Change is constant! Evolutionary studies show that organisms evolve by adapting to ever-changing environmental conditions. It is therefore critical for an animal's survival to detect a diverse array of cues. This unique phenomenon of adaptation is attributed to synaptic plasticity [reviewed in Fusco and Minelli (2010)]. Consistent encounter with a stimulus reinforces neuronal wiring to ensure the appropriate biological activity, manifested as behavior [reviewed in Citri and Malenka (2008)]. Physiological activities coupled with biological events during behavior result from the interplay between the brain and the surroundings of an organism. The coordinated action of the neuronal connectome integrates information and directs behavioral responses. 
It is intriguing to understand how organisms perceive their environment to execute behaviors and learn from their experiences. Hence, behavioral studies have been of keen interest for researchers in the field of neuroscience. Various reports from the past few decades have made it possible to parse out certain intricacies associated with behaviors and the neuronal and synaptic changes behind these behaviors. These studies have laid the path for delving further to elucidate the mechanisms underlying nervous system processes that direct the required behavioral output. Recent advances in molecular tools have proved a boon for such studies, but several challenges of different magnitudes pose limitations. One of the main challenges is the brain's complex structure and function with millions of neurons and synaptic connections as seen in most organisms with complex behavioral outputs. To overcome this challenge, C. elegans has proved to be a pioneering organism.

The simple nervous system of a $C$. elegans hermaphrodite has just 302 neurons and has been completely reconstructed with electron microscopy (White et al., 1986). Further, C. elegans shows discrete, robust, and easily quantifiable behaviors, making it a suitable model system. Often, these behavioral studies in worms revolve around the wired neuronal network consisting of synaptic connections by small classical neurotransmitters. However, this review will focus on the non-wired neuronal network that involves the transmission of information by neuropeptidergic signaling. Unlike classical neurotransmitters that function through wiring transmission, neuropeptides function through volumetric transmissions and play a critical role in sustained biological responses (Sorensen et al., 2008; van den Pol, 2012). Neuropeptides are also known to modulate the activity of co-released neurotransmitters to increase or decrease the strength of synaptic signaling [reviewed in Russo (2017)]. Noteworthy is that these small peptides can also act as peptidergic hormones to regulate other bodily functions. Therefore, neuropeptides have been established as modulators of behavior in a wide range of animals. In C. elegans, neuropeptides are classified into three different families, viz, FMRFamide or FLP-like peptides (FLPs), Insulin-like peptides (ILPs), and Neuropeptide-like proteins (NLPs) [reviewed in Holden-Dye and Walker (2013)]. Evidence that these diverse neuropeptides play important roles in locomotion, mating, learning and memory, sleep and addiction is accumulating, but an integration has been lacking. Even though the functions of neuropeptides in C. elegans have been vigorously studied, relatively little is known about their modes of action in modulating behavior. Here, we attempt at piecing together the available information, to construct mechanistic models of behaviors regulated by neuropeptides. The list of all neuropeptides found in C. elegans that are discussed in this review can be found in Table 1 .

\section{Locomotion}

Locomotion is a fundamental life process for all organisms to survive and thrive. It is the basis for numerous behaviors like foraging, feeding, mating, escaping predators, sleep, migration, and dispersal [reviewed in Gjorgjieva et al. (2014)]. The locomotion pattern differs across organisms and involves
TABLE 1 | List of neuropeptides discussed in this review.

\begin{tabular}{|c|c|c|c|c|}
\hline S. no. & Neuropeptides & $\begin{array}{l}\text { Behavioral } \\
\text { defects } \\
\text { associated with } \\
\text { neuropeptide } \\
\text { mutants }\end{array}$ & $\begin{array}{l}\text { Receptor/s (if } \\
\text { known) }\end{array}$ & References \\
\hline 1. & FLP-1 & $\begin{array}{l}\text { Bending angle/fat } \\
\text { storage/food- } \\
\text { evoked foraging }\end{array}$ & $\begin{array}{c}\text { NPR-6/FRPR- } \\
\text { 7/NPR-4/NPR- } \\
9\end{array}$ & $\begin{array}{l}\text { Nelson et al. } \\
\text { (1998), Oranth } \\
\text { et al. (2018), Jia } \\
\text { and Sieburth } \\
\text { (2021) }\end{array}$ \\
\hline 2. & FLP-2 & Arousal & FRPR-18 & $\begin{array}{l}\text { Chen et al. } \\
\text { (2016) }\end{array}$ \\
\hline 3. & FLP-3 & Swimming & - & $\begin{array}{l}\text { Chang et al. } \\
\text { (2015) }\end{array}$ \\
\hline 4. & FLP-5 & Mating & - & $\begin{array}{l}\text { Lints et al. } \\
\text { (2004) }\end{array}$ \\
\hline 5. & FLP-6 & Mating & - & $\begin{array}{l}\text { Lints et al. } \\
\text { (2004) }\end{array}$ \\
\hline 6. & FLP-7 & $\begin{array}{l}\text { Feeding/fat } \\
\text { mobilization }\end{array}$ & NPR-22 & $\begin{array}{l}\text { Palamiuc et al. } \\
\text { (2017) }\end{array}$ \\
\hline 7. & FLP-8 & Mating & - & Liu et al. (2007) \\
\hline 8. & FLP-10 & Mating/swimming & - & $\begin{array}{l}\text { Liu et al. } \\
\text { (2007), Chang } \\
\text { et al. (2015) }\end{array}$ \\
\hline 9. & FLP-11 & Sleep & - & $\begin{array}{l}\text { Turek et al. } \\
\text { (2016) }\end{array}$ \\
\hline 10. & FLP-12 & Mating & - & Liu et al. (2007) \\
\hline 11. & FLP-13 & Sleep & FRPR-4 & $\begin{array}{l}\text { Nelson et al. } \\
\text { (2014), Nath } \\
\text { et al. (2016) }\end{array}$ \\
\hline 12. & FLP-17 & Feeding/mating & - & $\begin{array}{l}\text { Lints et al. } \\
\text { (2004), Dalliere } \\
\text { et al. (2016) }\end{array}$ \\
\hline 13. & FLP-18 & $\begin{array}{l}\text { Reversals/ } \\
\text { swimming/ } \\
\text { foraging/ } \\
\text { feeding }\end{array}$ & $\begin{array}{l}\text { NPR-1/NPR- } \\
\text { 4/NPR-5 }\end{array}$ & $\begin{array}{c}\text { Cohen et al. } \\
\text { (2009), Chang } \\
\text { et al. (2015), } \\
\text { Lemieux et al. } \\
\text { (2015), } \\
\text { Bhardwaj et al. } \\
(2018,2020)\end{array}$ \\
\hline 14. & FLP-20 & $\begin{array}{l}\text { Reversals/ } \\
\text { arousal/ } \\
\text { mating/ } \\
\text { learning and } \\
\text { memory }\end{array}$ & FRPR-3 & $\begin{array}{l}\text { Liu et al. (2007), } \\
\text { Li et al. (2013), } \\
\text { Rabinowitch } \\
\text { et al. (2016), } \\
\text { Chew et al. } \\
\text { (2018b) }\end{array}$ \\
\hline 15. & FLP-21 & Social feeding & NPR-1 & $\begin{array}{l}\text { Rogers et al. } \\
\text { (2003), Chang } \\
\text { et al. (2015) }\end{array}$ \\
\hline 16. & FLP-24 & Sleep & - & $\begin{array}{l}\text { Nath et al. } \\
\text { (2016) }\end{array}$ \\
\hline 17. & FLP-34 & $\begin{array}{l}\text { Learning and } \\
\text { memory }\end{array}$ & NPR-11 & $\begin{array}{l}\text { Fadda et al. } \\
\text { (2020) }\end{array}$ \\
\hline 18. & NLP-8 & Sleep & - & $\begin{array}{l}\text { Nath et al. } \\
\text { (2016) }\end{array}$ \\
\hline 19. & NLP-12 & $\begin{array}{l}\text { Number and } \\
\text { amplitude of } \\
\text { body } \\
\text { Bends/feeding/fat } \\
\text { storage }\end{array}$ & CKR-2 & $\begin{array}{c}\text { Janssen et al. } \\
\text { (2008), Hu et al. } \\
\text { (2011), } \\
\text { Bhattacharya } \\
\text { et al. (2014), } \\
\text { Pandey et al. } \\
\text { (2021) }\end{array}$ \\
\hline
\end{tabular}


TABLE 1 | (Continued)

\begin{tabular}{|c|c|c|c|c|}
\hline S. no. & Neuropeptides & $\begin{array}{l}\text { Behavioral } \\
\text { defects } \\
\text { associated with } \\
\text { neuropeptide } \\
\text { mutants }\end{array}$ & $\begin{array}{c}\text { Receptor/s (if } \\
\text { known) }\end{array}$ & References \\
\hline 20. & NLP-22 & Sleep & - & $\begin{array}{l}\text { Nelson et al. } \\
\text { (2013) }\end{array}$ \\
\hline 21. & NLP-24 & Feeding & NPR-17 & $\begin{array}{l}\text { Cheong et al. } \\
\qquad(2015)\end{array}$ \\
\hline 22. & NLP-38 & $\begin{array}{l}\text { Learning and } \\
\text { memory }\end{array}$ & SPRR-2 & $\begin{array}{l}\text { Peymen et al. } \\
\text { (2019) }\end{array}$ \\
\hline 23. & NLP-49 & $\begin{array}{l}\text { Number and } \\
\text { angle of body- } \\
\text { bends/arousal }\end{array}$ & SEB-3 & $\begin{array}{c}\text { Chew et al. } \\
(2018 \mathrm{a})\end{array}$ \\
\hline 24. & PDF-1, PDF-2 & $\begin{array}{l}\text { Mating/ } \\
\text { reversals/ } \\
\text { sleep and } \\
\text { lethargus }\end{array}$ & $\begin{array}{c}\text { PDFR-1/PDFR- } \\
2\end{array}$ & $\begin{array}{l}\text { Barrios et al. } \\
\text { (2012), Choi } \\
\text { et al. (2013), } \\
\text { Flavell et al. } \\
\text { (2013), Hilbert } \\
\text { and Kim (2018) }\end{array}$ \\
\hline 25. & INS-1 & Food adaptation & - & $\begin{array}{l}\text { Chalasani et al. } \\
\text { (2010), Dwyer } \\
\text { and Aamodt } \\
\text { (2013) }\end{array}$ \\
\hline 26. & INS-6 & $\begin{array}{l}\text { Olfactory } \\
\text { Learning }\end{array}$ & - & $\begin{array}{l}\text { Chen et al. } \\
\text { (2013) }\end{array}$ \\
\hline 27. & INS-7 & Learning & - & $\begin{array}{l}\text { Chen et al. } \\
\text { (2013) }\end{array}$ \\
\hline 28. & INS-11 & $\begin{array}{l}\text { Learning and } \\
\text { memory }\end{array}$ & - & $\begin{array}{l}\text { Lee and } \\
\text { Mylonakis } \\
(2017)\end{array}$ \\
\hline 29. & $\begin{array}{l}\text { Luqin-like } \\
\text { RYamide } \\
\text { peptides }\end{array}$ & $\begin{array}{l}\text { Food evoked } \\
\text { satiety }\end{array}$ & NPR-22 & $\begin{array}{l}\text { Ohno et al. } \\
\text { (2017) }\end{array}$ \\
\hline 30. & $\begin{array}{l}\text { Nematocin } \\
\text { (NTC-1) }\end{array}$ & Mating & NTR-1 & $\begin{array}{l}\text { Garrison et al. } \\
\qquad(2012)\end{array}$ \\
\hline 31. & RGBA-1 & Mating & NPR-28 & Yin et al. (2017) \\
\hline 32. & $\begin{array}{l}\text { Neuromeric-U } \\
(\mathrm{NMU})\end{array}$ & $\begin{array}{l}\text { Learning and } \\
\text { memory }\end{array}$ & NMUR-1 & $\begin{array}{l}\text { Watteyne et al. } \\
\qquad(2020)\end{array}$ \\
\hline
\end{tabular}

walking, running, flying, swimming, and crawling, depending upon the organism's body plan.

In C. elegans, locomotion is an integral part of nearly all behaviors. C. elegans move in a sinusoidal pattern as a result of the dorsoventral flexing of body wall muscles. The differential synaptic inputs on these muscles restricts the movement in these worms to dorsoventral turns. The propagation of sinusoidal waves determines the direction of motion (White et al., 1986). Movement in C. elegans is a combination of different motion patterns, including forward crawls, reverse crawl (also known as reversals, illustrated in Figure 1A), and omega $(\Omega)$ turns [sharp reorientation events in which the head almost touches the tail, illustrated in Figure 1B and in Gray et al. (2005)]. It is interesting to note here that the frequency of reversals and $\Omega$ turns is critical in shaping $C$. elegans trajectory while executing any locomotory behavior (Gray et al., 2005; Lopez-Cruz et al., 2019).

Locomotion, albeit a complex behavior controlled by wired and non-wired neuronal circuitry, and is regulated by environmental and internal factors. Although the cues and neuronal connectome controlling locomotion have been largely characterized, the underlying molecular mechanism remain to be fully elucidated (Gray et al., 2005; Piggott et al., 2011). Apart from the conventional small neurotransmitters, neuropeptides also play a critical role in shaping locomotion in response to perturbations in the system. Fundamental studies exploring the role of neuropeptides in locomotion were based on mutations in two genes required for formation of neuropeptides, EGL-3 (Proprotein convertase) and EGL-21 (Carboxypeptidase E). Proteins encoded by these genes are required for the maturation of neuropeptides into their functional forms (Kass et al., 2001; Jacob and Kaplan, 2003). Mutants in egl-3 and egl-21 show decreased sensitivity to the acetylcholine esterase inhibitor, aldicarb, as well as decreased acetylcholine (ACh) release in the presence of aldicarb at the neuromuscular junction (NMJ) (Jacob and Kaplan, 2003; Hu et al., 2011). Moreover, mutants in the neuropeptide $n l p-12$ show resistance to aldicarb, again suggesting that neuropeptides regulate the levels of acetylcholine at NMJ (Hu et al., 2011). NLP-12 (mammalian homolog of cholecystokinin), released from the DVA neuron, binds to its receptor CKR-2 on cholinergic motor neurons to allow for regulating $\mathrm{ACh}$ release at the $\mathrm{NMJ}$, this in turn regulates locomotion in C. elegans (Hu et al., 2011). NLP-12 also integrates dopamine and ACh signaling pathways as DVA is postsynaptic to the PDE dopaminergic neuron. This integrated pathway when activated, increases body bends and amplitude of sinusoidal wave during locomotion to promote dwelling while on food (body bends and amplitude are illustrated in Figure 2; Bhattacharya et al., 2014; Bhattacharya and Francis, 2015). In contrast, the absence of food is associated with reduced dopamine levels and dispersal behavior (Sawin et al., 2000). The circuitry for this behavior has been delineated by Oranth et al. (2018). They show that PDE inhibits the AVK interneuron through dopamine/DOP-3 signaling in the presence of food. AVK releases the FLP-1 neuropeptide, which binds to receptors NPR-6 and FRPR-7 on the ventral cord and head motor neurons. FLP-1 inhibits the motor neurons and promotes dispersal by reducing bending angles during locomotion. Previous studies have also shown that FLP-1 maintains the amplitude of sinusoidal waves (Nelson et al., 1998), rate of body bends during swimming (Chang et al., 2015; Buntschuh et al., 2018), and the excitationinhibition balance during locomotion (Stawicki et al., 2013). Another neuropeptide implicated in regulating body bends and bending angles is NLP-49. NLP-49 is released from the AVK interneuron and functions through the receptor SEB-3. Mutants in nlp-49 show reduced mid-body and hip bends, while NLP-49 overexpression leads to hyperactive locomotion (Chew et al., 2018a).

In addition to the parameters discussed above, other aspects of locomotion in $C$. elegans, including reversals, $\Omega$ turns, and speed are also modulated by neuropeptides. Reversals and $\Omega$ turns are essential for reorientation during foraging, mate search, and aversion. On the other hand, speed determines locomotion rate during aversion, arousal (a state of hyperactive locomotion), and sleep. Studies have implicated the FLP-18 neuropeptide in the control of reversal frequency and the reversal length 
A

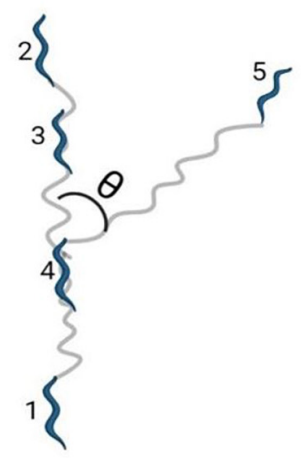

B

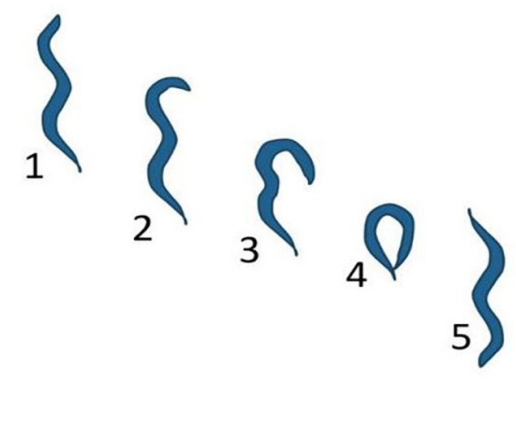

FIGURE 1 | Locomotion Pattern of $C$ elegans. (A) Shows reversals, where $\theta$ represents the bending angle during reorientation and the numbers $1-5$ indicate the stages of reversals in order (B) indicates an $\Omega$ turn where the numbers $1-5$ indicates the stages leading to an $\Omega$ turn in order. The images have been adapted from Gray et al. (2005).

(Cohen et al., 2009; Bhardwaj et al., 2018). FLP-18 functions through its receptors' NPR-1, NPR-4, and NPR-5. In $f l p-18$ mutants, reversal frequency decreases, and the reversal length increases during the local search (Cohen et al., 2009; Bhardwaj et al., 2018, 2020). This implies that $f l p-18$ mutants fail to perform local search effectively. Interestingly, the reversal frequency in $f l p-$ 18 mutants does not change significantly during the transition from local to global search (Cohen et al., 2009). As a result, global search is impaired in these animals. Various other neuropeptides modulate the dynamics of exploration. NLP-1 and INS-1 control the magnitude of reversals, where NLP-1 is released from the AWC sensory neurons, which also secretes glutamate. Both NLP1 and glutamate bind to their receptors NPR-11 and GLC-3, respectively, on the AIA interneuron. Glutamate/GLC-3 is an inhibitory synapse that promotes reversals, while NLP-1/NPR-11 reduces reversal frequency. INS-1, released from AIA neurons, modulates the activity of AWC neurons and functions in the same process as NLP-1 (Chalasani et al., 2010). Exploration is also modulated by genes encoding pigment dispersing factor signaling components, including PDF-1, PDF-2, and their receptor PDFR1. Mutants in $p d f-1, p d f-2$, or $p d f r-1$ fail to explore larger areas and show reduced speed (Flavell et al., 2013). Mutants in the galanin-like receptor npr-9 show decreased reversals, and $\Omega$ turns (Campbell et al., 2016). Previous studies in mice have shown that perfusion of the Galanin-like peptide (GALP) reduces locomotor activity in mice (Kauffman et al., 2005). Another neuropeptide, FLP-20 ensures the C. elegans stay on

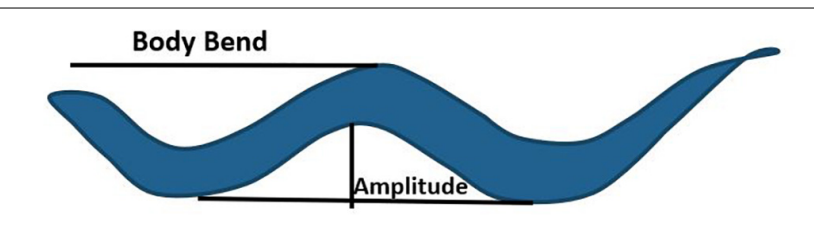

FIGURE 2 | Body bend and amplitude of a sinusoidal wave during locomotion in C. elegans. The image has been adapted fromPandey et al. (2021). food by decreasing reversal frequency. $f l p-20$ mutants show an increased reversal rate in off food conditions, suggesting its role in promoting dispersal (Rabinowitch et al., 2016). Delving further into the functioning of FLP-20, it has been reported to modulate speed during arousal in response to a mechanosensory stimuli. FLP-20 functions through FRPR-3, which acts in the RID interneuron (Chew et al., 2018b). The RID neuron, being a specialized neuroendocrine cell, releases the neuropeptide FLP14, required for maintaining forward movement. Mutants in $f l p-14$ have impaired forward movement and exhibit frequent pauses and increased reversal frequency (Lim et al., 2016). The function of some of these neuropeptides is illustrated in Figure 3. FLP-2 (functional analog of mammalian orexin) and PDF-1 have also been reported to modulate locomotion during arousal where FLP-2 functions through the receptor FRPR-18, a functional analog of mammalian orexin type-2 receptor (Chen et al., 2016). Behaviors like developmentally timed quiescence and sleep require reduced locomotor activity. These behaviors require the function of multiple neuropeptides, including FLP11, FLP-24, FLP-13, NLP-8, and NLP-22 that regulate stopping of locomotion during quiescence and sleep (Nelson et al., 2013, 2014; Nath et al., 2016; Steuer Costa et al., 2019). Mating in C. elegans requires turning back or reversing during copulation and inhibition of reorientations during mate search. PDF-1 is required to inhibit reorientation in males during mate search to explore large areas (Janssen et al., 2009; Barrios et al., 2012). Neuropeptides including FLP-8, FLP-10, FLP-12, and FLP-20 regulate turning during mating (Liu et al., 2007).

In addition to solid substrates, C. elegans also inhabit liquid media and use swimming as their mode of locomotion in liquid. Several neuropeptides have been implicated in regulating the swimming rate of $C$. elegans. The swimming rate is quantified as the number of body bends per unit time. Mutants in $f l p-18, f l p-$ 3 , $f l p-10$, and $f l p-21$ show increased swimming rates, while $f l p-9$ mutants show the opposite phenotype of lower swimming rate (Chang et al., 2015).

Apart from C. elegans, neuropeptides regulate locomotion in arthropods, mollusks, and vertebrate systems (Henry et al., 2000; 


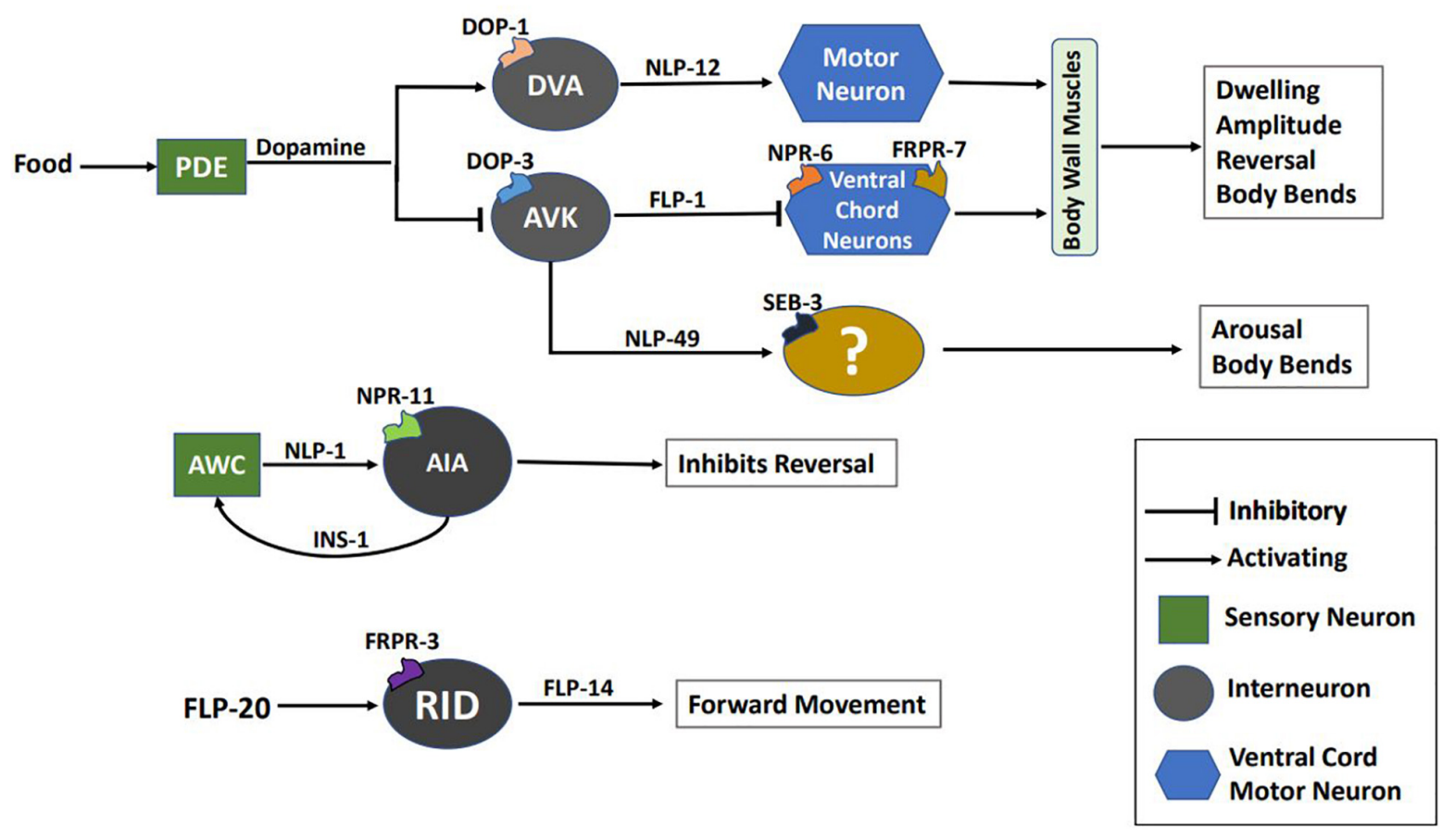

FIGURE 3 | Schematic of multiple neuropeptidergic circuits underlying locomotion. This image has been partially adapted from Oranth et al. (2018).

Kahsai et al., 2010b; Li et al., 2015). Some of these neuropeptidergic signaling pathways are conserved across phyla. In Drosophila melanogaster, the neuropeptide, Drosophila tachykinin (DTK) provides spatial orientation during exploration while another neuropeptide, short neuropeptide F (sNPF), finetunes locomotion and regulates speed of the animal (Kahsai et al., 2010a). In migratory locusts, Locusta migratoria, two related neuropeptides NPF1a and NPF2, regulate locomotion during the transition of the locust from solitary to the swarming phase (Hou et al., 2017). In mice, neuropeptide $S$ functions through the corticotropin releasing factor receptor 1 (CRF1) to increase locomotory activity (Li et al., 2015). CRF1 shows similarity in structure and function with the SEB-3 GPCR in C. elegans (Jee et al., 2013). Several mood-related disorders like anxiety and depression are attributed to dysregulation of CRF signaling [reviewed in Arborelius et al. (1999)]. Another group of neuropeptides that are opiodergic including enkephalin and dynorphin have been shown to control locomotion and dyskinesia in parkinsonian rat models (Sgroi et al., 2016).

The discussed observations imply that neuropeptides play a vital role during locomotion and dysregulation in neuropeptidergic signaling could result in severe locomotory defects. The presence of some conserved signaling pathways allows researchers to extrapolate these circuits to vertebrates and humans to start to unravel the complex wiring of locomotion circuitry involving neuropeptides.

\section{Feeding Behavior}

Feeding is an indispensable process for survival, influencing a wide range of behavioral repertoire by an organism. Despite its simple structure, C. elegans exhibits a variety of physiological and behavioral changes in response to food availability and nutritional status. For instance, behaviors like foraging, mating, egg-laying, dauer formation, quiescence, social interactions, etc., are affected by the feeding state of the animal [reviewed in Avery and You (2012), Barrios (2014)]. Caenorhabditis elegans is a bacterivorous worm, largely maintained on a slow-growing strain of E. coli bacteria, i.e., OP50 strain under standard laboratory conditions. It ingests the bacterial food through pumping and peristaltic movements of the pharynx [reviewed in Avery and You (2012)]. The feeding process and related behaviors are highly regulated by neuromodulators released by the somatic and pharyngeal nervous systems. These comprise of many neuropeptides and biogenic amines such as serotonin, octopamine, tyramine, etc., which control feeding and locomotion in a food-dependent manner (Horvitz et al., 1982; Rex et al., 2004; Alkema et al., 2005; Suo et al., 2006). The study of neuropeptide processing mutants, i.e., egl-3 and egl-21, paved the way to understand the importance of neuropeptides in feeding and/or fat storage [(Husson et al., 2006, 2007) and reviewed in Holden-Dye and Walker (2013); Srinivasan (2020)]. Further, the significance of neuropeptides is established by the neuropeptide release mutants, unc-31 that exhibit constitutive pharyngeal pumping during starvation, suggesting an underlying reduction in neuromodulation (Avery et al., 1993; Dalliere et al., 2016).

Literature has reported the role of diverse neuropeptides such as FLPs, ILPs, and NLPs in the feeding circuit. The widely expressed family of FLP neuropeptides act on GPCR receptors to modulate feeding behavior in C. elegans. For instance, FLP1 is implicated in fat storage and diet-induced changes in 
antioxidant responses mediated via the NPR-4 receptors in the intestine (Mutlu et al., 2020; Jia and Sieburth, 2021). Also, npr4 mutants result in impaired foraging behavior, fat homeostasis, and food preference (Cohen et al., 2009; Yu et al., 2016; Bhardwaj et al., 2018). Another allatostatin/galanin-like GPCR, viz, NPR9 impinges on the AIB interneurons to regulate food-evoked foraging, which, in turn, may affect metabolism and fat storage (Bendena et al., 2008). Interestingly, the FLP-18 neuropeptide has been found to act on different GPCRs to regulate a variety of feeding-related functions, i.e., FLP-18 binds to NPR-4 receptors to regulate fat accumulation in the intestine and modulate foraging behavior in the RIV and AVA neurons (Cohen et al., 2009). Moreover, NPR-5 receptors mediate the effects of FLP18 in the ciliated sensory neurons to induce lipid storage in ASJ neurons to regulate dauer formation and in ADF neurons to stimulate feeding (Cohen et al., 2009; Lemieux et al., 2015). Multiple features of feeding behaviors are illustrated in Figure 4. Further, FLP-18 and FLP-21 are implicated in the social feeding behavior, by associating with the different isoforms of NPR-1 receptors (de Bono and Bargmann, 1998; Rogers et al., 2003). It is noteworthy that the NPR-1 receptor is an evolutionary conserved Neuropeptide Y (NPY) receptor, known for its role in regulating feeding in vertebrates [reviewed in Beck (2006)]. NPY and its receptor defects have been shown to contribute to eating disorders such as anorexia nervosa and obesity [reviewed in Gehlert (1999), Zhang et al. (2012)].

More recent studies have shown that a tachykinin-like peptide, FLP-7, secreted by the ASI neurons has been found to act on the intestinal NPR-22 receptors to promote fat mobilization (Palamiuc et al., 2017). The pharyngeal circuit in C. elegans also secretes FLP-17A and FLP-17B neuropeptides, indicating their possible role in promoting feeding (Dalliere et al., 2016). A group of highly conserved insulin-like neuropeptides has been shown to determine the on and off states during pharyngeal pumping in $C$. elegans. These include INS-1 peptide, which acts by increasing the 5-HT sensitivity and insulin signaling pathway mutants, i.e., daf-2 and daf-18 mutants involved in promoting feeding adaptation (Dwyer and Aamodt, 2013; Dillon et al., 2016). Insulin-based regulation of feeding is extremely important as its malfunctioning could result in several metabolic disorders such as obesity, heart disease, and diabetes [reviewed in Kolb et al. (2020)]. Intriguingly and showing similarities to vertebrate systems, C. elegans possess endogenous opioids like NLP-24 that act through the opioid receptor, NPR-17, to modulate feeding by stimulating pharyngeal pumping during starvation in worms (Cheong et al., 2015). Moreover, feeding states have been found to influence decision-making between attractive and aversive stimuli along with foraging via PDF2/PDFR-1 dependent neuropeptidergic signaling (Ghosh et al., 2016; O'Donnell et al., 2018). In parallel, the Luqin-like RYamide peptides secreted from the pharyngeal M1 and M2 neurons, induce food-evoked satiety as a negative feedback loop. These peptides primarily exert their actions via the NPR-22 receptors on the feeding pacemaker $\mathrm{MC}$ and serotonergic $\mathrm{RIH}$ neurons (Ohno et al., 2017).

The identification of highly conserved cholecystokinin (CCK)-gastrin-like peptides, viz, DYRPLQFamide (NLP-12a) and DGYRPLQFamide (NLP-12b) in C. elegans has helped to illuminate the pathways of satiety transmission and fat storage in mammals. Janssen et al. report that the $n l p-12$ and $c k r-2$ receptor mutants show an increased fat accumulation, indicating a mechanism operating by alleviated metabolism of fat stores (Janssen et al., 2008). The functional conservation of CCKs is also complemented by another study, where expression of the mammalian CCK-8 degrading enzyme, tripeptidyl peptidase II (TPPII) in C. elegans fat cells resulted in decreased fat accumulation (McKay et al., 2007).

Despite noteworthy strides in functionally characterizing the roles of neuropeptides in regulating feeding behavior, their numerous non-cell-autonomous endocrine effects are yet to be understood. Future investigations in this area could aid in addressing prevailing metabolic disorders such as obesity, diabetes, etc.

\section{Mating Behavior}

Caenorhabditis elegans mating is a complex behavior, comprising of the coordinated execution of spatio-temporal motor actions. In an androdioecious species like $C$. elegans, males initiate and execute the mating process while hermaphrodites essentially play a passive role [reviewed in Sherlekar and Lints (2014)]. Of the total 385 neurons present in the C. elegans male, at least 79 are known to facilitate mating (Liu and Sternberg, 1995; MolinaGarcia et al., 2020). The stereotyped mating begins due to the influence of chemical pheromones, i.e., ascarosides which attract the male to contact and scan its mate for detecting the vulva [reviewed in Chute and Srinivasan (2014)]. Once the vulva is located, the male stops scanning and inserts its protracted copulatory spicules inside the hermaphrodite animal to transfer sperm [reviewed in Barr and Garcia (2006)]. Thus, the mating process involves five different steps: mate identification, reversals, repetitive turning, vulva detection, and finally intromission (illustrated in Figure 5). A plethora of literature indicates the role of neurotransmitters like dopamine, serotonin, octopamine, etc., in regulating mating behaviors in C. elegans. While dopamine is involved in the mating motivation, sperm transfer, and recovery from post-coital lethargy, serotonin influences the ventral-tail curling during male turning (Loer and Kenyon, 1993; Carnell et al., 2005; Correa et al., 2012; LeBoeuf et al., 2014). On the other hand, octopamine, the biological equivalent of norepinephrine in invertebrates, acts downstream of dopamine to regulate the locomotor activity state in copulating mates (Suo et al., 2019).

Apart from neurotransmitters, neuropeptides are known to play a pivotal role in modulating the mating circuit. Here, we review the neuropeptides implicated in mating behaviors of C. elegans. The alleged role of neuropeptides in this behavior was initially observed by examining the neuropeptide processing egl-3 mutants, defective in egg-laying and other mechanosensory responses that could be important during mating (Kass et al., 2001). The commencing step of the mating process, i.e., mate-searching behavior is regulated by the PDF-1 (Pigmentdispersing factor) neuropeptide released by the AIM neuron, which promotes the expression of DAF-7/TGF $\beta$ in the malespecific ASJ neurons. PDF-1 modulation circuit also extends to URY, PQR, and PHA neurons due to PDFR-1 receptor expression 


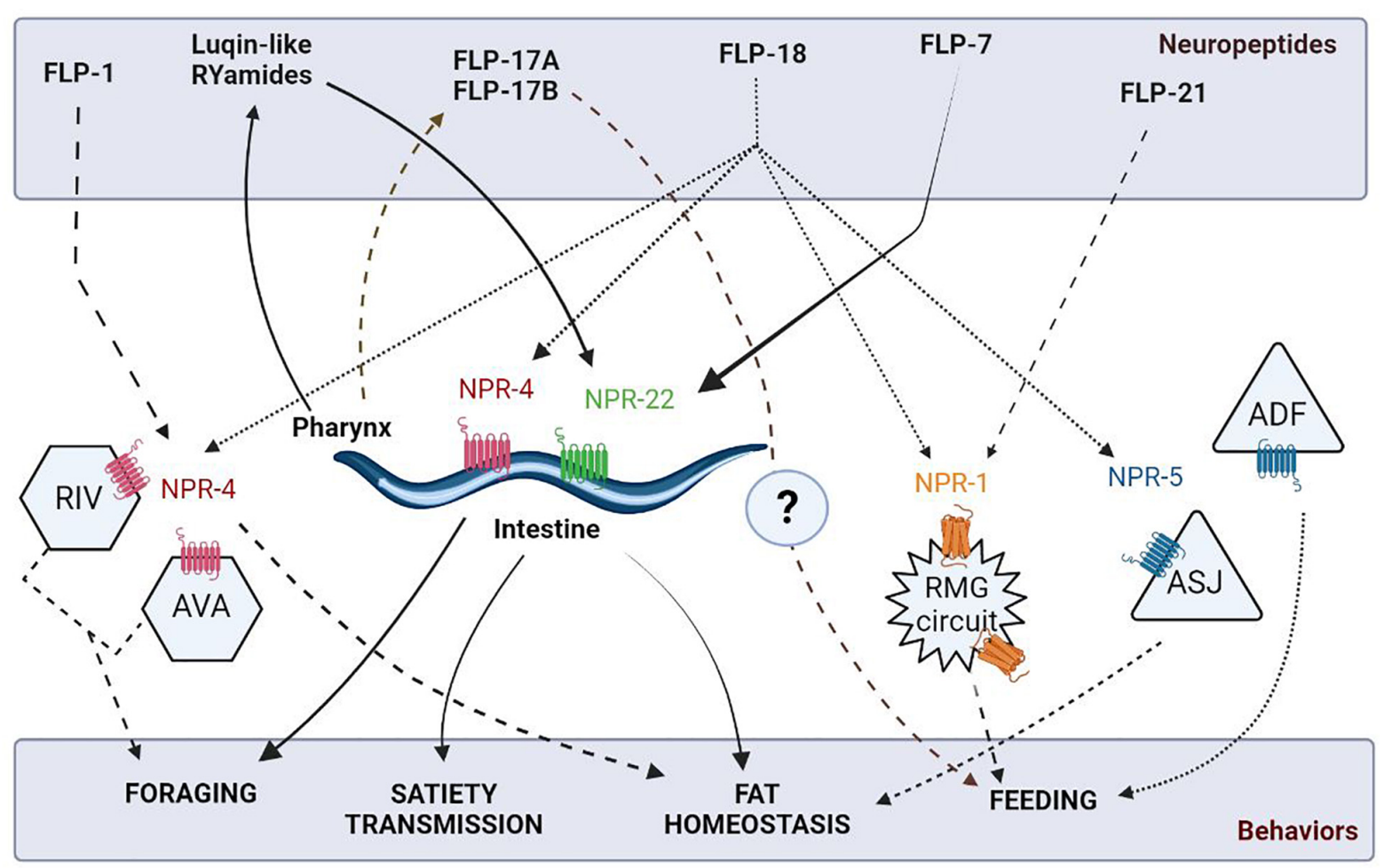

FIGURE 4 | Schematic of neuropeptidergic circuits underlying feeding related behaviors. The figure has been adapted from Cohen et al. (2009).

in these neurons (Barrios et al., 2012; Hilbert and Kim, 2018). Interestingly, PDF-1 also displays phylogenetic conservation in other organisms, for instance, regulation of male sex drive in Drosophila melanogaster (Fujii and Amrein, 2010). Further, defects in the orthologs of PDFR-1 receptors in humans are known to result in anhedonia-related disorders such as bipolar disorder and post-traumatic stress disorders (Soria et al., 2010; Ressler et al., 2011).

The function of neuropeptides in the mating process is further established by the neuropeptide-release unc-31 mutants, required for the release of Dense-core vesicles (DCVs). These mutants are unable to initiate spicule insertion and hence, fail to transfer sperms into the vulva. However, the other steps of mating behavior remain unaffected in $u n c-31$ mutants (LeBoeuf and Garcia, 2017). In addition, the coherence of all these mating steps is governed by the oxytocin/vasopressin-like peptide known as nematocin. Nematocin (NTC-1) is released by the male ray DVA neuron and acts on the NTR-1 receptor to promote response to the potential mates and integrate different steps of the mating behavior (Garrison et al., 2012). In most species studied, these oxytocin-related neuropeptides display genetic and functional conservation in reproduction-related behaviors, such as selection of mate, copulation and offspring care (Wagenaar et al., 2010; Melis and Argiolas, 2011; Garrison et al., 2012; Marlin et al., 2015). Apart from oxytocin/vasopressin like peptides, the FLP neuropeptides including FLP-5, FLP-6, and FLP-17 are suggested to modulate the spicule circuit upon stimulation of the male RnA ray neurons (Lints et al., 2004).
Liu et al. (2007), have additionally shown that FLP-8, FLP10, FLP-12, and FLP-20 neuropeptides participate in sensory transduction during male sexual turning behaviors. In parallel, a FLP neuropeptide orthologs in Drosophila, i.e., neuropeptide F and the mammalian neuropeptide $\mathrm{Y}$ are known to influence male courtship (Lee et al., 2006). More recent work has shown that gliaderived neuropeptides in C. elegans potentially explain the agerelated decline in male mating behaviors, RGBA-1 neuropeptides acting on the NPR-28 receptor in serotonergic and dopaminergic neurons influence mating efficiency. Noteworthy is that the polymorphic alleles of the rgba-1 gene are associated with male virility and were found to alleviate mating behavior deterioration in aging worms (Yin et al., 2017). The fact that diverse neuropeptides are involved in the multiple overlapping steps of mating behaviors, highlights the intricate ways by which they modulate the mating circuit. However, it is unclear how these neuropeptides differentially participate in the anticipatory phase, i.e., arousal in response to pheromones and instinctive drive, or the consummatory phase, i.e., execution of the mating process.

\section{Sleep-Like Behavior}

Molecular mechanisms underlying sleep have been studied using multiple model organisms including invertebrate models like Drosophila melanogaster, and Danio rerio (Hendricks et al., 2000; Shaw et al., 2000; Zhdanova et al., 2001; Mackiewicz et al., 2008). A quiescent state known as lethargus before each molt during development is referred to as developmentally timed sleep (DTS, illustrated in Figure 6). Caenorhabditis elegans also 


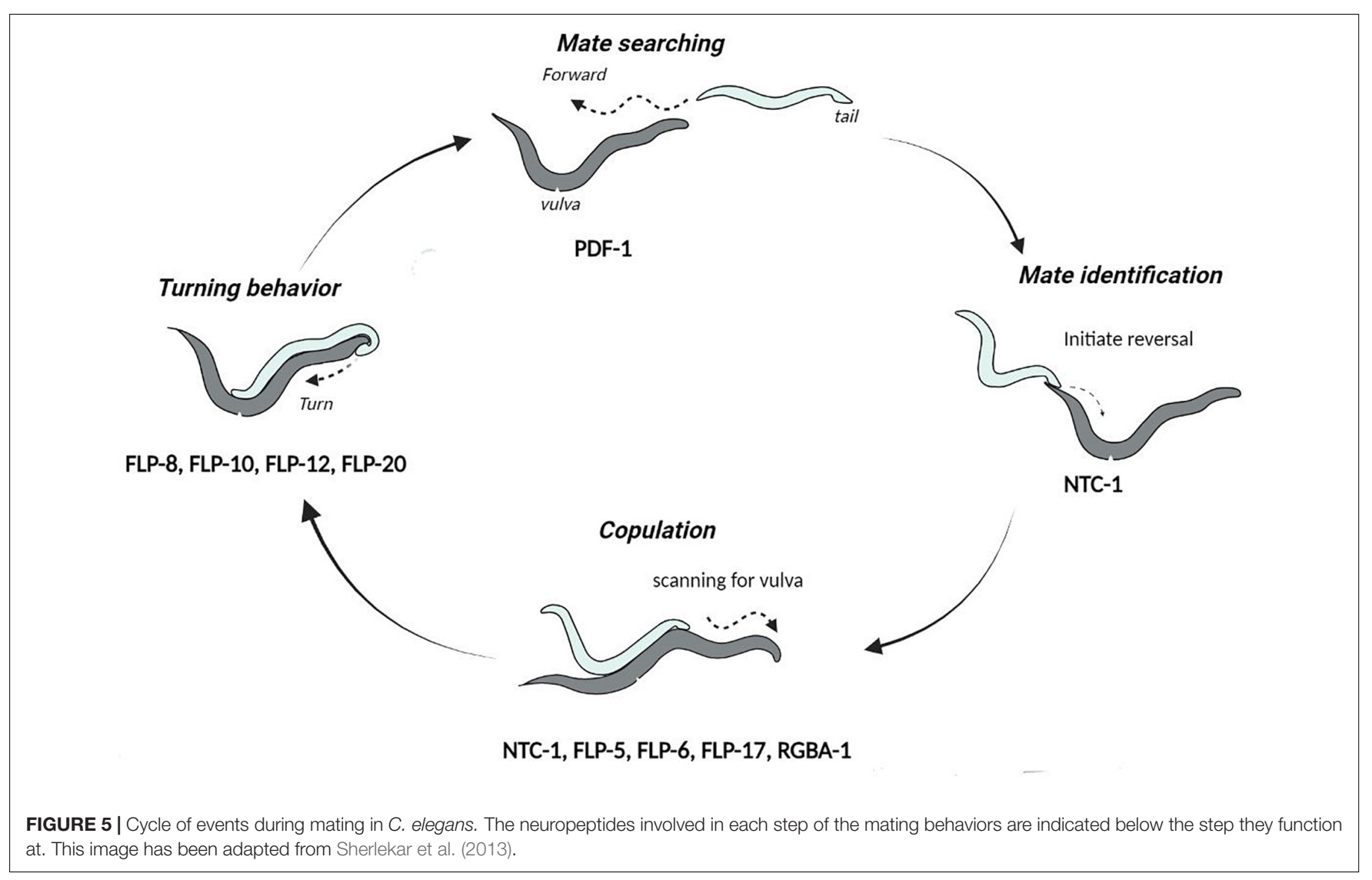

shows a state of sleep-like quiescent behavior during which there is a temporary halt in locomotion, pharyngeal pumping, head movement, defecation and feeding [(Cassada and Russell, 1975; Nath et al., 2016) and illustrated in Figure 6].

Caenorhabditis elegans has been used as a model for studying lethargus behaviors induced by a variety of genes. For instance, cyclic guanosine monophosphate (cGMP) dependent protein kinase (EGL-4) boosts sleep-like state in C. elegans (Raizen et al., 2008). Neuropeptides play an important role in the sleep/wake cycle of vertebrates [reviewed in Sutcliffe and de Lecea (2002)]. However, mechanistic insights into neuropeptide function in sleep-like behavior comes in large part from work on D. melanogaster and C. elegans. In Drosophila the Pigment-Dispersing Factor (PDF) neuropeptide is responsible for normal circadian rhythm (Renn et al., 1999). Caenorhabditis elegans also secrete PDF-1 from the RMG neuronal circuit and the secretion of PDF-1 is lowered during lethargus (Choi et al., 2013). Neuropeptide NLP-22, structurally similar to the mammalian Neuromedin S peptide (NMS), released from the RIA interneuron allows for sleep-like behavior and functions through protein kinase A (PKA) dependent mechanisms (Nelson et al., 2013) and illustrated in Figure 7A.

Apart from DTS, cellular stress like heat, cold, tissue damage, and hypertonicity also results in a stress-induced quiescence state or stress-Induced sleep (SIS) in C elegans, [(Hill et al., 2014) and illustrated in Figure 4]. Again, neuropeptides play a crucial role in SIS-like behavior. The neuropeptide receptor
NPR-1 modulates heat stress-induced sleep-like behavior during hyperoxic conditions (Soto et al., 2019). Heat stress causes the release of LIN-3/EGF, which acts on its receptor LET23/EGFR present on the ALA neuron, triggering the release of FLP-13 neuropeptide that is required for feeding and locomotory quiescent behavior (Nelson et al., 2014). The FLP-13 neuropeptide released from the ALA neuron as a result of stress acts on the receptor FRPR-4 on the DVA neuron to modulate the posture of the animals during quiescence (Nelson et al., 2015). The transcription factor LIM-6 controls both peptidergic and GABAergic function in the RIS neuron. LIM-6 maintains the expression of the APTF-1 transcription factor, which in turn upregulates the expression of FLP-11 neuropeptide required for sleep behavior in RIS neurons (Turek et al., 2016). Studies have also shown that triple mutants in the neuropeptides $n l p-8, f l p$ 24 , and $f l p-13$ synergistically inhibit SIS-like behavior (Nath et al., 2016). This experiment shows that different neuropeptidergic signaling mechanisms could contribute collectively toward sleep behavior (illustrated in Figure 7B).

Neuropeptidergic control of sleep is conserved in higher organisms as well. In zebrafish multiple neuropeptides maturing from proprotein RFamide neuropeptide VF (NPVF) act synergistically to promote sleep (Lee et al., 2017). NPY has been shown to modulate sleep patterns in rats and also affects sleep endocrine systems in patients facing depression (Held et al., 2006; Szentirmai and Krueger, 2006). Neuropeptide-S, an evolutionary conserved neuropeptide regulates sleep-wake 

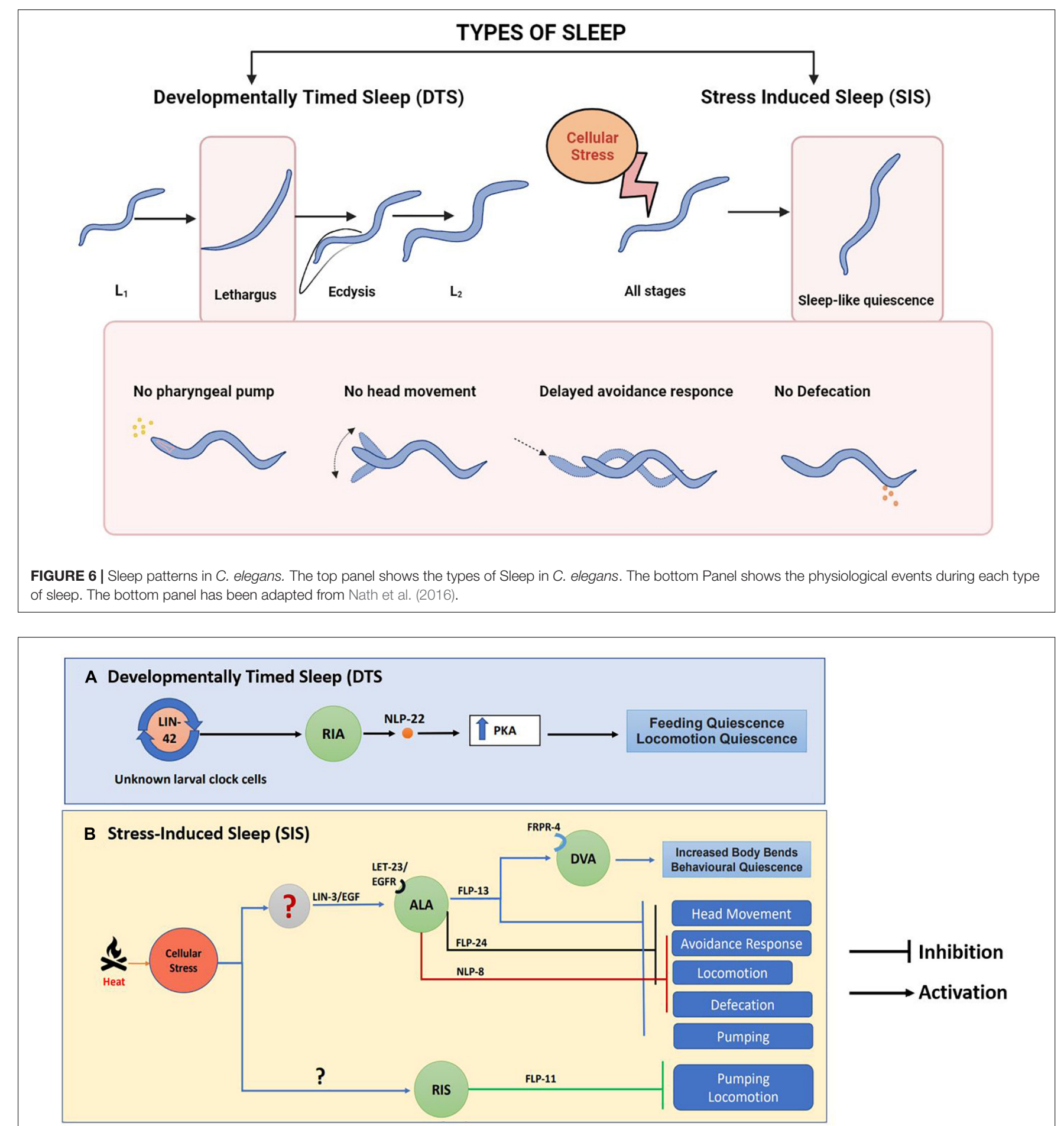

FIGURE 7 | Neuropeptide circuitry regulating sleep. The image indicates (A) Developmentally Timed Sleep (DTS) and (B) Stress Induced Sleep (SIS) along with the neuropeptides involved in each process. This image has been adapted from work by Nelson et al. (2013, 2014) and Nath et al. (2016).

cycle in mammals (Xu et al., 2004). Another neuropeptide hypocretin (also known as orexin) promotes wakefulness and inhibits sleep in mammals [reviewed in Soya and Sakurai (2020)]. Narcolepsy, a neurological condition affecting sleep has been associates with dysregulation of orexin signaling. The discovery of these neuropeptidergic pathways in invertebrates and vertebrate models, can answer many questions related to molecular mechanisms underlying sleep and hence may 
be of importance in the field of neuropsychiatric disorders related to sleep.

\section{Learning and Memory}

Learning and memory are crucial biological properties for an organism to survive in its habitat. Multiple invertebrate models are used for understanding the mechanisms behind memory and learning (Carew and Sahley, 1986). For instance, C. elegans and D. melanogaster allow for intricate genetic manipulations of the nervous system, which in turn can provide insight into molecular mechanisms involved in the process of memory formation and cognitive functions (Cerutti and Levin, 2006).

Caenorhabditis elegans typically shows two types of learning, associative learning and non-associative learning that induce different degrees of memory based on the training paradigms used (Wen et al., 1997; Morrison et al., 1999). Different paradigms could result in Long-Term Memory (LTM), Short-Term Memory (STM), and Intermediate-Term Memory (ITM) (Rose et al., 2002, 2003; Steidl et al., 2003; Li et al., 2013; Dahiya et al., 2019). Another important learning paradigm involves understanding the interactions between $C$. elegans with their surrounding microbes. For instance, C. elegans can detect and discriminate infectious microbes like Pseudomonas aeruginosa, through its innate immune system [reviewed in Nicholas and Hodgkin (2004)].

Pathogen avoidance learning is known to be dependent on signaling through insulin-like peptides (ILPs), such as INS-11, secreted by the intestinal cells (Lee and Mylonakis, 2017). During this process ILPs act through different sets of neurons for sensing external signals, for instance, INS16 through the pheromone-sensing neuron ADL and INS-4 through the bacteria-sensing neuron AWA (Wu et al., 2019). Further, FLP-20 has been reported to be required for STM in the mechanosensory neurons after mass training ( $\mathrm{Li}$ et al., 2013). FLP-20 neuropeptides from primary mechanosensory neurons bind to their receptor FRPR -3 which is present on the neuroendocrine cell RID, thus controlling arousal behavior in C. elegans (Chew et al., 2018b). Further, the NeuropeptideLike Protein-38 (NLP-38)/Myo Inhibitory Peptide (MIP) signal activates the $G$ protein-coupled receptor SPRR-2 which is responsible for salt aversive learning (Peymen et al., 2019). The evolutionarily conserved Neuromeric U (NMU) neuropeptide family homolog CAPA-1 in C. elegans, is secreted from ASG neurons and alongwith its receptor NMUR-1 is required for the retrieval of learned salt avoidance behavior (Watteyne et al., 2020). In order to promote learning, ILPs have been shown to play antagonistic roles. Chen et al., have reported that INS-6 from ASI neurons suppresses the expression of INS-7 in URX neurons to enable learning (Chen et al., 2013). Similarly, FLP-34, released from the serotonergic neurons, acts through the NPR-11 receptor on the AIA interneuron for negative associative learning (Fadda et al., 2020).

Interestingly, the administration of one such neuropeptide, i.e., Neuropeptide S (NPS) into the APP/PSI mouse model of Alzheimer's disease (AD), has been shown to result in the reduction of $\beta$-Amyloid plaques indicating the clinical relevance of employing neuropeptides in treating age related disorders of the brain (Zhao et al., 2019). Neuropeptide S is also shown to promote olfactory, and spatial memory in rodent models (Wang et al., 2020). These studies bring out the importance of understanding the role of neuropeptides in different forms of learning and memory.

\section{Addiction Behavior}

Substance abuse is a growing concern of societies around the world. It refers to the illicit and/or excessive use of psychoactive drugs, including alcohol. Chronic use of these drugs alters the expression of several key players in the neuronal substrate resulting in a state of tolerance and gradual addiction. Apart from voluntary priming to these drugs, stress has been attributed to one of the leading causes of addiction [reviewed in Schank et al. (2012)]. Alcohol is a commonly used drug, and the physiological effects associated with it have been studied extensively. Alcohol induces effects in a dose-dependent manner ranging from dysregulation in limb coordination, impaired speech at lower doses to even death at higher doses. Although several genes are implicated in addiction behavior, the mechanism by which binge episodes of alcohol consumption lead to addiction, however, remain largely elusive. Caenorhabditis elegans shows sedation and defects in locomotion in response to alcohol at a concentration similar to that seen in humans (Davies et al., 2003; Mitchell et al., 2007; Pandey et al., 2021). Therefore, C. elegans, with a simple nervous system and easy genetic manipulation, serves as a good model system for studying addiction behaviors and their underlying molecular mechanism. Caenorhabditis elegans exhibit multiple behaviors in response to attractant or aversive cues. Chemotaxis and locomotion changes are some of the wellestablished behaviors that can be utilized for addiction studies. In this part of the review, we will be focusing on the role of neuropeptides in addiction.

Most studies regarding addiction focus on circuitry that controls tolerance, withdrawal, and relapse pathways. Dopamine signaling, for that matter, has been well studied [reviewed in Wise (2004), Hyman et al. (2006)]. Another important gene encoding the calcium sensitive potassium (BK) channel has gained attention as one of the key players in addiction behavior. BK channels are activated to mediate behavioral responses to alcohol with mechanisms that may be conserved across multiple systems (Davies et al., 2003; Pietrzykowski and Treistman, 2008; Kreifeldt et al., 2013; Velazquez-Marrero et al., 2016).

The role of neuropeptides in addiction related behaviors is poorly understood. However, hints indicating possible roles for neuropeptides in addictive behaviors in vertebrate systems and C. elegans have started to emerge (Mitchell et al., 2010; Schank et al., 2012). An intriguing study by Thiele et al., has opened a new avenue indicating the role of neuropeptide signaling in addiction. They show that neuropeptide Y (NPY) levels inversely control the ethanol intake and resistance in rats. The study further reports that animals lacking NPY are resistant to ethanol induced effects even though the plasma concentration of ethanol is similar to controls showing the behavior (Thiele et al., 1998). Infusion of NPY in CNS also shows reduced intake of alcohol post tolerance in rats (Thorsell et al., 2007). Previous evidence 
has indicated that NPY levels are higher in ethanol preferring rats than in ethanol non-preferring animals (Ehlers et al., 1998). This neuroadaptive circuit functioning through NPY is conserved, and in C. elegans acts through NPY receptor-like protein, NPR-1. Ethanol exposure leads to downregulation of the NPR-1 pathway suggesting that the development of acute tolerance is negatively regulated by NPR-1 signaling (Davies et al., 2004).

Addiction-related withdrawal and relapse are mainly associated with a negative emotional state of elevated anxiety and stress and CRF, being a stress neuropeptide, has been shown to mediate these behaviors [reviewed in Heilig and Koob (2007), Koob (2008)]. The levels of CFR increase during the ethanol withdrawal period and subsequently decrease after ethanol intake (Merlo Pich et al., 1995; Olive et al., 2002). The withdrawal related anxiogenic effect is relieved in animals treated with CRF antagonist alarmin or alpha-helical CRF confirming the role of CFR in withdrawal associated behavior (Rassnick et al., 1993; Funk and Koob, 2007). As discussed till now, it is clear that CFR and NPY exert opposing effects in ethanol related behaviors. The mechanism for this antagonism was parsed out recently (Pleil et al., 2015). These exciting results show that NPY activation inhibits CFR neurons through a $\mathrm{G}_{i}$-mediated PKA-dependent postsynaptic mechanism to reduce withdrawal response and ethanol intake. Likewise, in C. elegans, a CFR receptor-like protein, SEB-3, positively regulates acute tolerance to ethanol. SEB-3 is a potential receptor for neuropeptide NLP-49 and mutants in seb-3 $(g f)$ phenocopy withdrawal behavior showing increased tremors in C. elegans (Jee et al., 2013). Endogenous cannabinoid signaling has also been parsed out in C. elegans. A putative neuropeptide receptor NPR-19 (mammalian homolog of $\mathrm{CB}_{1}$ receptor) mediates the cannabinoid signaling in these animals and inhibits the aversive response to nociception (Oakes et al., 2019).

The puzzle is still far from complete, and many more pieces are yet to be found. Although neuropeptide research regarding addiction has recently gained momentum, a plethora of questions remains unanswered. Interesting to note here is that several candidate ligands of neuropeptide receptors, already implicated in addiction, are potential candidates for screening. Moreover, neuropeptides released in response to stress and regulating arousal can be interesting molecules for further studies. Even though some receptors are known to play an essential role in ethanol-induced behavior, their site of action and their circuitry are still largely unknown. Together, these findings and further work with multiple model organisms can serve an important role in designing potential therapeutics to treat relapse and reward behaviors associated with substance abuse.

\section{CONCLUSION}

Organisms bring change in their activities in response to both intrinsic and extrinsic cues. These changes are referred to as the organism's behavior. In this review, we have summarized the results from various studies to understand the complex mechanisms underlying behaviors and how neuropeptides regulate them. We also provide insight into multiple neuropeptide-based behaviors using C. elegans as a model system. Neuropeptides, once released, are not reuptaken and therefore continue transmitting information until they are degraded or their signal is inhibited [reviewed in Russo (2017)]. Hence, neuropeptides are interesting molecules to study sustained physiological responses. In this regard, neuropeptides are emerging as crucial modulators of several behaviors, including some discussed in this review.

As discussed in this review, neuropeptidergic signaling plays a pivotal role in relaying the information between the neurons during the execution of behaviors and is conserved across the phyla. For instance, Neuropeptide $\mathrm{Y}$ is one of the major neuromodulators of feeding, sleep, memory, and learning in humans. Likewise, in C. elegans, Neuropeptide Y/RFamide- like receptors called NPR regulates a broad spectrum of behaviors, including feeding, locomotion, mating, etc., Neuropeptide or neuropeptide receptor mutants show behavioral defects which can be easily scored as a phenotype for analyses. These behavioral studies have helped in developing several C. elegans disease models to extrapolate the findings to human diseases. Caenorhabditis elegans based disease models for multiple conditions including epilepsy, autism and neurodegenerative disorders continue to allow is to understand the molecular pathways and biomarkers associated with these diseases (Dexter et al., 2012; Wong et al., 2018; Rawsthorne et al., 2021).

With emerging researchers' interest in investigating the role of neuropeptides in relation to behavioral studies, a plethora of questions remain unanswered. (1) How multiple neuropeptides act in concert to execute a particular behavior? (2) Identifying the pleiotropic effects of a neuropeptide through its multiple sites of action. (3) Deciphering the crosstalk between different neuropeptides during complex behaviors. (4) Understanding stimulus-response relationship due to slow and extended-release of neuropeptides.

Addressing these and other questions will help to elucidate the complex mechanism of behaviors and could allow for developing therapeutic strategies to treat the disorders associated with defects in neuropeptide signaling.

\section{AUTHOR CONTRIBUTIONS}

UB, NS, and SS researched and wrote the manuscript. KB supervised and helped editing the manuscript. All authors contributed to the article and approved the submitted version.

\section{FUNDING}

UB was funded by a Department of Biotechnology (DBT), Senior Research Fellowship (SRF) and NS was funded by a Council of Scientific and Industrial Research (CSIR) SRF. SS was funded through DBT and DBT/Welcome Trust India Alliance (IA) grants awarded to $\mathrm{KB}$. $\mathrm{KB}$ was funded by Indian Institute of Science (IISc), Bangalore intramural funds, IA grant IA/S/19/2/504649, DBT grants BT/PR24038/BRB/10/1693/2018 and BT/HRD-NBA-NWB/38/2019-20, and the Ministry of Education grant MoE/STARS-1/454. 


\section{REFERENCES}

Alkema, M. J., Hunter-Ensor, M., Ringstad, N., and Horvitz, H. R. (2005). Tyramine Functions independently of octopamine in the Caenorhabditis elegans nervous system. Neuron 46, 247-260. doi: 10.1016/j.neuron.2005.02. 024

Arborelius, L., Owens, M. J., Plotsky, P. M., and Nemeroff, C. B. (1999). The role of corticotropin-releasing factor in depression and anxiety disorders. J. Endocrinol. 160, 1-12. doi: 10.1677/joe.0.1600001

Avery, L., Bargmann, C. I., and Horvitz, H. R. (1993). The Caenorhabditis elegans unc-31 gene affects multiple nervous system-controlled functions. Genetics 134, 455-464. doi: 10.1093/genetics/134.2.455

Avery, L., and You, Y. J. (2012). “C. elegans feeding," in WormBook, ed The C. elegans Research Community (Rockville, MD: Genetics Society of America). doi: 10.1895/wormbook.1.150.1

Barr, M. M., and Garcia, L. R. (2006). "Male mating behavior," in WormBook, The C. elegans Research Community (Rockville, MD: Genetics Society of America). doi: 10.1895/wormbook.1.78.1

Barrios, A. (2014). Exploratory decisions of the Caenorhabditis elegans male: a conflict of two drives. Semin. Cell Dev. Biol. 33, 10-17. doi: 10.1016/j.semcdb. 2014.06.003

Barrios, A., Ghosh, R., Fang, C., Emmons, S. W., and Barr, M. M. (2012). PDF-1 neuropeptide signaling modulates a neural circuit for mate-searching behavior in C. elegans. Nat. Neurosci. 15, 1675-1682. doi: 10.1038/nn.3253

Beck, B. (2006). Neuropeptide Y in normal eating and in genetic and dietaryinduced obesity. Philos. Trans. R. Soc. Lond. B Biol. Sci. 361, 1159-1185. doi: 10.1098/rstb.2006.1855

Bendena, W. G., Boudreau, J. R., Papanicolaou, T., Maltby, M., Tobe, S. S., and Chin-Sang, I. D. (2008). A Caenorhabditis elegans allatostatin/galanin-like receptor NPR-9 inhibits local search behavior in response to feeding cues. Proc Natl. Acad. Sci. U. S. A. 105, 1339-1342. doi: 10.1073/pnas.0709492105

Bhardwaj, A., Pandey, P., and Babu, K. (2020). Control of Locomotory Behavior of Caenorhabditis elegans by the Immunoglobulin Superfamily Protein RIG-3. Genetics 214, 135-145. doi: 10.1534/genetics.119.302872

Bhardwaj, A., Thapliyal, S., Dahiya, Y., and Babu, K. (2018). FLP-18 Functions through the G-Protein-Coupled Receptors NPR-1 and NPR-4 to Modulate Reversal Length in Caenorhabditis elegans. J. Neurosci. 38, 4641-4654. doi: 10.1523/JNEUROSCI.1955-17.2018

Bhattacharya, R., and Francis, M. M. (2015). In the proper context: neuropeptide regulation of behavioral transitions during food searching. Worm 4:e1062971. doi: 10.1080/21624054.2015.1062971

Bhattacharya, R., Touroutine, D., Barbagallo, B., Climer, J., Lambert, C. M., Clark, C. M., et al. (2014). A conserved dopamine-cholecystokinin signaling pathway shapes context-dependent Caenorhabditis elegans behavior. PLoS Genet. 10:e1004584. doi: 10.1371/journal.pgen.1004584

Buntschuh, I., Raps, D. A., Joseph, I., Reid, C., Chait, A., Totanes, R., et al. (2018). FLP-1 neuropeptides modulate sensory and motor circuits in the nematode Caenorhabditis elegans. PLoS One 13:e0189320. doi: 10.1371/journal. pone. 0189320

Campbell, J. C., Polan-Couillard, L. F., Chin-Sang, I. D., and Bendena, W. G. (2016). NPR-9, a Galanin-Like G-Protein Coupled Receptor, and GLR-1 Regulate Interneuronal Circuitry Underlying Multisensory Integration of Environmental Cues in Caenorhabditis elegans. PLoS Genet. 12:e1006050. doi: 10.1371/journal.pgen.1006050

Carew, T. J., and Sahley, C. L. (1986). Invertebrate learning and memory: from behavior to molecules. Annu. Rev. Neurosci. 9, 435-487.

Carnell, L., Illi, J., Hong, S. W., and McIntire, S. L. (2005). The G-proteincoupled serotonin receptor SER-1 regulates egg laying and male mating behaviors in Caenorhabditis elegans. J. Neurosci. 25, 10671-10681. doi: 10.1523/ JNEUROSCI.3399-05.2005

Cassada, R. C., and Russell, R. L. (1975). The dauerlarva, a post-embryonic developmental variant of the nematode Caenorhabditis elegans. Dev. Biol. 46, 326-342. doi: 10.1016/0012-1606(75)90109-8

Cerutti, D. T., and Levin, E. D. (2006). "Cognitive Impairment Models Using Complementary Species," in Animal Models of Cognitive Impairment, eds E. D. Levin and J. J. Buccafusco (Boca Raton (FL): CRC Press).

Chalasani, S. H., Kato, S., Albrecht, D. R., Nakagawa, T., Abbott, L. F., and Bargmann, C. I. (2010). Neuropeptide feedback modifies odor-evoked dynamics in Caenorhabditis elegans olfactory neurons. Nat. Neurosci. 13, 615 621. doi: $10.1038 / \mathrm{nn} .2526$

Chang, Y. J., Burton, T., Ha, L., Huang, Z., Olajubelo, A., and Li, C. (2015). Modulation of Locomotion and Reproduction by FLP Neuropeptides in the Nematode Caenorhabditis elegans. PLoS One 10:e0135164. doi: 10.1371/journal. pone. 0135164

Chen, D., Taylor, K. P., Hall, Q., and Kaplan, J. M. (2016). The Neuropeptides FLP2 and PDF-1 Act in Concert To Arouse Caenorhabditis elegans Locomotion. Genetics 204, 1151-1159. doi: 10.1534/genetics.116.192898

Chen, Z., Hendricks, M., Cornils, A., Maier, W., Alcedo, J., and Zhang, Y. (2013). Two insulin-like peptides antagonistically regulate aversive olfactory learning in C. elegans. Neuron 77, 572-585. doi: 10.1016/j.neuron.2012.11.025

Cheong, M. C., Artyukhin, A. B., You, Y. J., and Avery, L. (2015). An opioid-like system regulating feeding behavior in C. elegans. Elife 4:e06683. doi: 10.7554/ eLife.06683

Chew, Y. L., Grundy, L. J., Brown, A. E. X., Beets, I., and Schafer, W. R. (2018a). Neuropeptides encoded by $n l p-49$ modulate locomotion, arousal and egg-laying behaviours in Caenorhabditis elegans via the receptor SEB-3. Philos. Trans. $R$. Soc. Lond. B Biol. Sci. 373:20170368. doi: 10.1098/rstb.2017.0368

Chew, Y. L., Tanizawa, Y., Cho, Y., Zhao, B., Yu, A. J., Ardiel, E. L., et al. (2018b). An Afferent Neuropeptide System Transmits Mechanosensory Signals Triggering Sensitization and Arousal in C. elegans. Neuron 99, 1233-1246.e6. doi: 10.1016/j.neuron.2018.08.003

Choi, S., Chatzigeorgiou, M., Taylor, K. P., Schafer, W. R., and Kaplan, J. M. (2013). Analysis of NPR-1 reveals a circuit mechanism for behavioral quiescence in C. elegans. Neuron 78, 869-880. doi: 10.1016/j.neuron.2013.04.002

Chute, C. D., and Srinivasan, J. (2014). Chemical mating cues in C. elegans. Semin. Cell Dev. Biol. 33, 18-24. doi: 10.1016/j.semcdb.2014.06.002

Citri, A., and Malenka, R. C. (2008). Synaptic plasticity: multiple forms, functions, and mechanisms. Neuropsychopharmacology 33, 18-41. doi: 10.1038/sj.npp. 1301559

Cohen, M., Reale, V., Olofsson, B., Knights, A., Evans, P., and de Bono, M. (2009). Coordinated regulation of foraging and metabolism in C. elegans by RFamide neuropeptide signaling. Cell Metab. 9, 375-385. doi: 10.1016/j.cmet.2009.02. 003

Correa, P., LeBoeuf, B., and Garcia, L. R. (2012). C. elegans dopaminergic D2like receptors delimit recurrent cholinergic-mediated motor programs during a goal-oriented behavior. PLoS Genet. 8:e1003015. doi: 10.1371/journal.pgen. 1003015

Dahiya, Y., Rose, S., Thapliyal, S., Bhardwaj, S., Prasad, M., and Babu, K. (2019). Differential Regulation of Innate and Learned Behavior by Creb1/Crh-1 in Caenorhabditis elegans. J. Neurosci. 39, 7934-7946. doi: 10.1523/JNEUROSCI. 0006-19.2019

Dalliere, N., Bhatla, N., Luedtke, Z., Ma, D. K., Woolman, J., Walker, R. J., et al. (2016). Multiple excitatory and inhibitory neural signals converge to fine-tune Caenorhabditis elegans feeding to food availability. FASEB J. 30, 836-848. doi: 10.1096/fj.15-279257

Davies, A. G., Bettinger, J. C., Thiele, T. R., Judy, M. E., and McIntire, S. L. (2004). Natural variation in the npr-1 gene modifies ethanol responses of wild strains of C. elegans. Neuron 42, 731-743. doi: 10.1016/j.neuron.2004.05.004

Davies, A. G., Pierce-Shimomura, J. T., Kim, H., VanHoven, M. K., Thiele, T. R., Bonci, A., et al. (2003). A central role of the BK potassium channel in behavioral responses to ethanol in C. elegans. Cell 115, 655-666. doi: 10.1016/s00928674(03)00979-6

de Bono, M., and Bargmann, C. I. (1998). Natural variation in a neuropeptide Y receptor homolog modifies social behavior and food response in C. elegans. Cell 94, 679-689. doi: 10.1016/s0092-8674(00)81609-8

Dexter, P. M., Caldwell, K. A., and Caldwell, G. A. (2012). A predictable worm: application of Caenorhabditis elegans for mechanistic investigation of movement disorders. Neurotherapeutics 9, 393-404. doi: 10.1007/s13311-0120109-x

Dillon, J., Holden-Dye, L., O’Connor, V., and Hopper, N. A. (2016). Contextdependent regulation of feeding behaviour by the insulin receptor, DAF-2, in Caenorhabditis elegans. Invert. Neurosci. 16:4. doi: 10.1007/s10158-016-0187-2

Dwyer, D. S., and Aamodt, E. J. (2013). Insulin/IGF-1 signaling, including class II/III PI3Ks, beta-arrestin and SGK-1, is required in C. elegans to maintain pharyngeal muscle performance during starvation. PLoS One 8:e63851. doi: 10.1371/journal.pone.0063851 
Ehlers, C. L., Li, T. K., Lumeng, L., Hwang, B. H., Somes, C., Jimenez, P., et al. (1998). Neuropeptide Y levels in ethanol-naive alcohol-preferring and nonpreferring rats and in Wistar rats after ethanol exposure. Alcohol. Clin. Exp. Res. 22, 1778-1782. doi: 10.1111/j.1530-0277.1998.tb03979.x

Fadda, M., De Fruyt, N., Borghgraef, C., Watteyne, J., Peymen, K., Vandewyer, E., et al. (2020). NPY/NPF-Related Neuropeptide FLP-34 Signals from Serotonergic Neurons to Modulate Aversive Olfactory Learning in Caenorhabditis elegans. J. Neurosci. 40, 6018-6034. doi: 10.1523/JNEUROSCI.2674-19.2020

Flavell, S. W., Pokala, N., Macosko, E. Z., Albrecht, D. R., Larsch, J., and Bargmann, C. I. (2013). Serotonin and the neuropeptide PDF initiate and extend opposing behavioral states in C. elegans. Cell 154, 1023-1035. doi: 10.1016/j.cell.2013.08. 001

Fujii, S., and Amrein, H. (2010). Ventral lateral and DN1 clock neurons mediate distinct properties of male sex drive rhythm in Drosophila. Proc. Natl. Acad. Sci. U. S. A. 107, 10590-10595. doi: 10.1073/pnas.0912457107

Funk, C. K., and Koob, G. F. (2007). A CRF(2) agonist administered into the central nucleus of the amygdala decreases ethanol self-administration in ethanoldependent rats. Brain Res. 1155, 172-178. doi: 10.1016/j.brainres.2007.04. 009

Fusco, G., and Minelli, A. (2010). Phenotypic plasticity in development and evolution: facts and concepts. Introduction. Philos. Trans. R. Soc. Lond. B Biol. Sci. 365, 547-556. doi: 10.1098/rstb.2009.0267

Garrison, J. L., Macosko, E. Z., Bernstein, S., Pokala, N., Albrecht, D. R., and Bargmann, C. I. (2012). Oxytocin/vasopressin-related peptides have an ancient role in reproductive behavior. Science 338, 540-543. doi: 10.1126/science. 1226201

Gehlert, D. R. (1999). Role of hypothalamic neuropeptide $\mathrm{Y}$ in feeding and obesity. Neuropeptides 33, 329-338. doi: 10.1054/npep.1999.0057

Ghosh, D. D., Sanders, T., Hong, S., McCurdy, L. Y., Chase, D. L., Cohen, N., et al. (2016). Neural Architecture of Hunger-Dependent Multisensory Decision Making in C. elegans. Neuron 92, 1049-1062. doi: 10.1016/j.neuron.2016.10. 030

Gjorgjieva, J., Biron, D., and Haspel, G. (2014). Neurobiology of Caenorhabditis elegans Locomotion: where Do We Stand? Bioscience 64, 476-486. doi: 10.1093/ biosci/biu058

Gray, J. M., Hill, J. J., and Bargmann, C. I. (2005). A circuit for navigation in Caenorhabditis elegans. Proc. Natl. Acad. Sci. U. S. A. 102, 3184-3191. doi: 10.1073/pnas.0409009101

Heilig, M., and Koob, G. F. (2007). A key role for corticotropin-releasing factor in alcohol dependence. Trends Neurosci. 30, 399-406.

Held, K., Antonijevic, I., Murck, H., Kuenzel, H., and Steiger, A. (2006). Neuropeptide Y (NPY) shortens sleep latency but does not suppress ACTH and cortisol in depressed patients and normal controls. Psychoneuroendocrinology 31, 100-107. doi: 10.1016/j.psyneuen.2005.05.015

Hendricks, J. C., Finn, S. M., Panckeri, K. A., Chavkin, J., Williams, J. A., Sehgal, A., et al. (2000). Rest in Drosophila is a sleep-like state. Neuron 25, 129-138.

Henry, J., Zatylny, C., and Favrel, P. (2000). HPLC and electrospray ionization mass spectrometry as tools for the identification of APGWamide-related peptides in gastropod and bivalve mollusks: comparative activities on Mytilus muscles. Brain Res. 862, 162-170. doi: 10.1016/s0006-8993(00)02108-9

Hilbert, Z. A., and Kim, D. H. (2018). PDF-1 neuropeptide signaling regulates sexually dimorphic gene expression in shared sensory neurons of C. elegans. Elife 7:e36547. doi: 10.7554/eLife.36547

Hill, A. J., Mansfield, R., Lopez, J. M., Raizen, D. M., and Van Buskirk, C. (2014). Cellular stress induces a protective sleep-like state in C. elegans. Curr. Biol. 24, 2399-2405. doi: 10.1016/j.cub.2014.08.040

Holden-Dye, L., and Walker, R. J. (2013). The roles of neuropeptides in Caenorhabditis elegans including their importance in the regulation of feeding and metabolism. Protein Pept. Lett. 20, 636-646. doi: 10.2174/ 0929866511320060004

Horvitz, H. R., Chalfie, M., Trent, C., Sulston, J. E., and Evans, P. D. (1982). Serotonin and octopamine in the nematode Caenorhabditis elegans. Science 216, 1012-1014. doi: 10.1126/science.6805073

Hou, L., Yang, P., Jiang, F., Liu, Q., Wang, X., and Kang, L. (2017). The neuropeptide $\mathrm{F} /$ nitric oxide pathway is essential for shaping locomotor plasticity underlying locust phase transition. Elife 6:e22526. doi: 10.7554/eLife. 22526
Hu, Z., Pym, E. C., Babu, K., Vashlishan Murray, A. B., and Kaplan, J. M. (2011). A neuropeptide-mediated stretch response links muscle contraction to changes in neurotransmitter release. Neuron 71, 92-102. doi: 10.1016/j.neuron.2011.04. 021

Husson, S. J., Clynen, E., Baggerman, G., Janssen, T., and Schoofs, L. (2006). Defective processing of neuropeptide precursors in Caenorhabditis elegans lacking proprotein convertase 2 (KPC-2/EGL-3): mutant analysis by mass spectrometry. J. Neurochem. 98, 1999-2012. doi: 10.1111/j.1471-4159.2006. 04014.x

Husson, S. J., Janssen, T., Baggerman, G., Bogert, B., Kahn-Kirby, A. H., Ashrafi, K., et al. (2007). Impaired processing of FLP and NLP peptides in carboxypeptidase E (EGL-21)-deficient Caenorhabditis elegans as analyzed by mass spectrometry. J. Neurochem. 102, 246-260. doi: 10.1111/j.1471-4159.2007.0 4474.x

Hyman, S. E., Malenka, R. C., and Nestler, E. J. (2006). Neural mechanisms of addiction: the role of reward-related learning and memory. Annu. Rev. Neurosci. 29, 565-598. doi: 10.1146/annurev.neuro.29.051605.1 13009

Jacob, T. C., and Kaplan, J. M. (2003). The EGL-21 carboxypeptidase E facilitates acetylcholine release at Caenorhabditis elegans neuromuscular junctions. J. Neurosci. 23, 2122-2130. doi: 10.1523/JNEUROSCI.23-06-02122.2003

Janssen, T., Husson, S. J., Meelkop, E., Temmerman, L., Lindemans, M., Verstraelen, K., et al. (2009). Discovery and characterization of a conserved pigment dispersing factor-like neuropeptide pathway in Caenorhabditis elegans. J. Neurochem. 111, 228-241. doi: 10.1111/j.1471-4159.2009.06323.x

Janssen, T., Meelkop, E., Lindemans, M., Verstraelen, K., Husson, S. J., Temmerman, L., et al. (2008). Discovery of a cholecystokinin-gastrin-like signaling system in nematodes. Endocrinology 149, 2826-2839. doi: 10.1210/ en.2007- 1772

Jee, C., Lee, J., Lim, J. P., Parry, D., Messing, R. O., and McIntire, S. L. (2013). SEB-3, a CRF receptor-like GPCR, regulates locomotor activity states, stress responses and ethanol tolerance in Caenorhabditis elegans. Genes Brain Behav. 12, 250-262. doi: 10.1111/j.1601-183X.2012.00829.x

Jia, Q., and Sieburth, D. (2021). Mitochondrial hydrogen peroxide positively regulates neuropeptide secretion during diet-induced activation of the oxidative stress response. Nat. Commun. 12:2304. doi: 10.1038/s41467-021-22561-x

Kahsai, L., Martin, J. R., and Winther, A. M. (2010b). Neuropeptides in the Drosophila central complex in modulation of locomotor behavior. J. Exp. Biol. 213, 2256-2265. doi: 10.1242/jeb.043190

Kahsai, L., Kapan, N., Dircksen, H., Winther, A. M., and Nassel, D. R. (2010a). Metabolic stress responses in Drosophila are modulated by brain neurosecretory cells that produce multiple neuropeptides. PLoS One 5:e11480. doi: 10.1371/journal.pone.0011480

Kass, J., Jacob, T. C., Kim, P., and Kaplan, J. M. (2001). The EGL-3 proprotein convertase regulates mechanosensory responses of Caenorhabditis elegans. J. Neurosci. 21, 9265-9272. doi: 10.1523/JNEUROSCI.21-23-09265.2001

Kauffman, A. S., Buenzle, J., Fraley, G. S., and Rissman, E. F. (2005). Effects of galanin-like peptide (GALP) on locomotion, reproduction, and body weight in female and male mice. Horm. Behav. 48, 141-151. doi: 10.1016/j.yhbeh.2005. 01.010

Kolb, H., Kempf, K., Rohling, M., and Martin, S. (2020). Insulin: too much of a good thing is bad. BMC Med. 18:224. doi: 10.1186/s12916-020-01688-6

Koob, G. F. (2008). A role for brain stress systems in addiction. Neuron 59, 11-34 doi: 10.1016/j.neuron.2008.06.012

Kreifeldt, M., Le, D., Treistman, S. N., Koob, G. F., and Contet, C. (2013). BK channel betal and beta4 auxiliary subunits exert opposite influences on escalated ethanol drinking in dependent mice. Front. Integr. Neurosci. 7:105. doi: 10.3389/fnint.2013.00105

LeBoeuf, B., Correa, P., Jee, C., and Garcia, L. R. (2014). Caenorhabditis elegans male sensory-motor neurons and dopaminergic support cells couple ejaculation and post-ejaculatory behaviors. Elife 3:e02938. doi: 10.7554/eLife. 02938

LeBoeuf, B., and Garcia, L. R. (2017). Caenorhabditis elegans Male Copulation Circuitry Incorporates Sex-Shared Defecation Components To Promote Intromission and Sperm Transfer. G3 7, 647-662. doi: 10.1534/g3.116.036756

Lee, D. A., Andreev, A., Truong, T. V., Chen, A., Hill, A. J., Oikonomou, G., et al. (2017). Genetic and neuronal regulation of sleep by neuropeptide VF. Elife 6:e25727. 
Lee, G., Bahn, J. H., and Park, J. H. (2006). Sex- and clock-controlled expression of the neuropeptide F gene in Drosophila. Proc. Natl. Acad. Sci. U. S. A. 103, 12580-12585. doi: 10.1073/pnas.0601171103

Lee, K., and Mylonakis, E. (2017). An Intestine-Derived Neuropeptide Controls Avoidance Behavior in Caenorhabditis elegans. Cell Rep. 20, 2501-2512. doi: 10.1016/j.celrep.2017.08.053

Lemieux, G. A., Cunningham, K. A., Lin, L., Mayer, F., Werb, Z., and Ashrafi, K. (2015). Kynurenic acid is a nutritional cue that enables behavioral plasticity. Cell 160, 119-131. doi: 10.1016/j.cell.2014.12.028

Li, C., Timbers, T. A., Rose, J. K., Bozorgmehr, T., McEwan, A., and Rankin, C. H. (2013). The FMRFamide-related neuropeptide FLP-20 is required in the mechanosensory neurons during memory for massed training in C. elegans. Learn. Mem. 20, 103-108. doi: 10.1101/lm.028993.112

Li, M. S., Peng, Y. L., Jiang, J. H., Xue, H. X., Wang, P., Zhang, P. J., et al. (2015). Neuropeptide S Increases locomotion activity through corticotropinreleasing factor receptor 1 in substantia nigra of mice. Peptides 71, 196-201. doi: 10.1016/j.peptides.2015.07.024

Lim, M. A., Chitturi, J., Laskova, V., Meng, J., Findeis, D., Wiekenberg, A., et al. (2016). Neuroendocrine modulation sustains the C. elegans forward motor state. Elife 5:e19887.

Lints, R., Jia, L., Kim, K., Li, C., and Emmons, S. W. (2004). Axial patterning of C. elegans male sensilla identities by selector genes. Dev. Biol. 269, 137-151. doi: 10.1016/j.ydbio.2004.01.021

Liu, K. S., and Sternberg, P. W. (1995). Sensory regulation of male mating behavior in Caenorhabditis elegans. Neuron 14, 79-89. doi: 10.1016/0896-6273(95) 90242-2

Liu, T., Kim, K., Li, C., and Barr, M. M. (2007). FMRFamide-like neuropeptides and mechanosensory touch receptor neurons regulate male sexual turning behavior in Caenorhabditis elegans. J. Neurosci. 27, 7174-7182. doi: 10.1523/ JNEUROSCI.1405-07.2007

Loer, C. M., and Kenyon, C. J. (1993). Serotonin-deficient mutants and male mating behavior in the nematode Caenorhabditis elegans. J. Neurosci. 13, 5407-5417. doi: 10.1523/JNEUROSCI.13-12-05407.1993

Lopez-Cruz, A., Sordillo, A., Pokala, N., Liu, Q., McGrath, P. T., and Bargmann, C. I. (2019). Parallel Multimodal Circuits Control an Innate Foraging Behavior. Neuron 102, 407-419.e8. doi: 10.1016/j.neuron.2019.01.053

Mackiewicz, M., Naidoo, N., Zimmerman, J. E., and Pack, A. I. (2008). Molecular mechanisms of sleep and wakefulness. Ann. N. Y. Acad. Sci. 1129, 335-349.

Marlin, B. J., Mitre, M., D’Amour, J. A., Chao, M. V., and Froemke, R. C. (2015). Oxytocin enables maternal behaviour by balancing cortical inhibition. Nature 520, 499-504. doi: 10.1038/nature14402

McKay, R. M., McKay, J. P., Suh, J. M., Avery, L., and Graff, J. M. (2007). Tripeptidyl peptidase II promotes fat formation in a conserved fashion. EMBO Rep. 8, 1183-1189. doi: 10.1038/sj.embor.7401086

Melis, M. R., and Argiolas, A. (2011). Central control of penile erection: a revisitation of the role of oxytocin and its interaction with dopamine and glutamic acid in male rats. Neurosci. Biobehav. Rev. 35, 939-955. doi: 10.1016/ j.neubiorev.2010.10.014

Merlo Pich, E., Lorang, M., Yeganeh, M., Rodriguez de Fonseca, F., Raber, J., Koob, G. F., et al. (1995). Increase of extracellular corticotropin-releasing factorlike immunoreactivity levels in the amygdala of awake rats during restraint stress and ethanol withdrawal as measured by microdialysis. J. Neurosci. 15, 5439-5447. doi: 10.1523/JNEUROSCI.15-08-05439.1995

Mitchell, P., Mould, R., Dillon, J., Glautier, S., Andrianakis, I., James, C., et al. (2010). A differential role for neuropeptides in acute and chronic adaptive responses to alcohol: behavioural and genetic analysis in Caenorhabditis elegans. PLoS One 5:e10422. doi: 10.1371/journal.pone.0010422

Mitchell, P. H., Bull, K., Glautier, S., Hopper, N. A., Holden-Dye, L., and O'Connor, V. (2007). The concentration-dependent effects of ethanol on Caenorhabditis elegans behaviour. Pharmacogenomics J. 7, 411-417. doi: 10.1038/sj.tpj.6500440

Molina-Garcia, L., Lloret-Fernandez, C., Cook, S. J., Kim, B., Bonnington, R. C., Sammut, M., et al. (2020). Direct glia-to-neuron transdifferentiation gives rise to a pair of male-specific neurons that ensure nimble male mating. Elife 9:e48361. doi: 10.7554/eLife.48361

Morrison, G. E., Wen, J. Y., Runciman, S., and van der Kooy, D. (1999). Olfactory associative learning in Caenorhabditis elegans is impaired in lrn-1 and lrn-2 mutants. Behav. Neurosci. 113, 358-367. doi: 10.1037//0735-7044.113.2.358
Mutlu, A. S., Gao, S. M., Zhang, H., and Wang, M. C. (2020). Olfactory specificity regulates lipid metabolism through neuroendocrine signaling in Caenorhabditis elegans. Nat. Commun. 11:1450. doi: 10.1038/s41467-020-15296-8

Nath, R. D., Chow, E. S., Wang, H., Schwarz, E. M., and Sternberg, P. W. (2016). C. elegans Stress-Induced Sleep Emerges from the Collective Action of Multiple Neuropeptides. Curr. Biol. 26, 2446-2455. doi: 10.1016/j.cub.2016.07.048

Nelson, L. S., Rosoff, M. L., and Li, C. (1998). Disruption of a neuropeptide gene, flp-1, causes multiple behavioral defects in Caenorhabditis elegans. Science 281, 1686-1690. doi: 10.1126/science.281.5383.1686

Nelson, M. D., Janssen, T., York, N., Lee, K. H., Schoofs, L., and Raizen, D. M. (2015). FRPR-4 Is a G-Protein Coupled Neuropeptide Receptor That Regulates Behavioral Quiescence and Posture in Caenorhabditis elegans. PLoS One 10:e0142938. doi: 10.1371/journal.pone.0142938

Nelson, M. D., Lee, K. H., Churgin, M. A., Hill, A. J., Van Buskirk, C., Fang-Yen, C., et al. (2014). FMRFamide-like FLP-13 neuropeptides promote quiescence following heat stress in Caenorhabditis elegans. Curr. Biol. 24, 2406-2410. doi: 10.1016/j.cub.2014.08.037

Nelson, M. D., Trojanowski, N. F., George-Raizen, J. B., Smith, C. J., Yu, C. C., Fang-Yen, C., et al. (2013). The neuropeptide NLP-22 regulates a sleep-like state in Caenorhabditis elegans. Nat. Commun. 4:2846. doi: 10.1038/ncomms3846

Nicholas, H. R., and Hodgkin, J. (2004). Responses to infection and possible recognition strategies in the innate immune system of Caenorhabditis elegans. Mol. Immunol. 41, 479-493. doi: 10.1016/j.molimm.2004.03.037

Oakes, M., Law, W. J., and Komuniecki, R. (2019). Cannabinoids Stimulate the TRP Channel-Dependent Release of Both Serotonin and Dopamine to Modulate Behavior in C. elegans. J. Neurosci. 39, 4142-4152. doi: 10.1523/JNEUROSCI. 2371-18.2019

O’Donnell, M. P., Chao, P. H., Kammenga, J. E., and Sengupta, P. (2018). Rictor/TORC2 mediates gut-to-brain signaling in the regulation of phenotypic plasticity in C. elegans. PLoS Genet. 14:e1007213. doi: 10.1371/journal.pgen. 1007213

Ohno, H., Yoshida, M., Sato, T., Kato, J., Miyazato, M., Kojima, M., et al. (2017). Luqin-like RYamide peptides regulate food-evoked responses in C. elegans. Elife 6:e28877. doi: 10.7554/eLife.28877

Olive, M. F., Koenig, H. N., Nannini, M. A., and Hodge, C. W. (2002). Elevated extracellular CRF levels in the bed nucleus of the stria terminalis during ethanol withdrawal and reduction by subsequent ethanol intake. Pharmacol. Biochem. Behav. 72, 213-220. doi: 10.1016/s0091-3057(01)00748-1

Oranth, A., Schultheis, C., Tolstenkov, O., Erbguth, K., Nagpal, J., Hain, D., et al. (2018). Food Sensation Modulates Locomotion by Dopamine and Neuropeptide Signaling in a Distributed Neuronal Network. Neuron 100, 14141428.e10. doi: 10.1016/j.neuron.2018.10.024

Palamiuc, L., Noble, T., Witham, E., Ratanpal, H., Vaughan, M., and Srinivasan, S. (2017). A tachykinin-like neuroendocrine signalling axis couples central serotonin action and nutrient sensing with peripheral lipid metabolism. Nat. Commun. 8:14237. doi: 10.1038/ncomms 14237

Pandey, P., Singh, A., Kaur, H., Ghosh-Roy, A., and Babu, K. (2021). Increased dopaminergic neurotransmission results in ethanol dependent sedative behaviors in Caenorhabditis elegans. PLoS Genet. 17:e1009346. doi: 10.1371/ journal.pgen.1009346

Peymen, K., Watteyne, J., Borghgraef, C., Van Sinay, E., Beets, I., and Schoofs, L. (2019). Myoinhibitory peptide signaling modulates aversive gustatory learning in Caenorhabditis elegans. PLoS Genet. 15:e1007945. doi: 10.1371/journal.pgen. 1007945

Pietrzykowski, A. Z., and Treistman, S. N. (2008). The molecular basis of tolerance. Alcohol. Res. Health 31, 298-309.

Piggott, B. J., Liu, J., Feng, Z., Wescott, S. A., and Xu, X. Z. (2011). The neural circuits and synaptic mechanisms underlying motor initiation in C. elegans. Cell 147, 922-933. doi: 10.1016/j.cell.2011.08.053

Pleil, K. E., Rinker, J. A., Lowery-Gionta, E. G., Mazzone, C. M., McCall, N. M., Kendra, A. M., et al. (2015). NPY signaling inhibits extended amygdala CRF neurons to suppress binge alcohol drinking. Nat. Neurosci. 18, 545-552. doi: 10.1038/nn.3972

Rabinowitch, I., Laurent, P., Zhao, B., Walker, D., Beets, I., Schoofs, L., et al. (2016). Neuropeptide-Driven Cross-Modal Plasticity following Sensory Loss in Caenorhabditis elegans. PLoS Biol. 14:e1002348. doi: 10.1371/journal.pbio. 1002348 
Raizen, D. M., Zimmerman, J. E., Maycock, M. H., Ta, U. D., You, Y. J., Sundaram, M. V., et al. (2008). Lethargus is a Caenorhabditis elegans sleep-like state. Nature 451, 569-572. doi: 10.1038/nature06535

Rassnick, S., Heinrichs, S. C., Britton, K. T., and Koob, G. F. (1993). Microinjection of a corticotropin-releasing factor antagonist into the central nucleus of the amygdala reverses anxiogenic-like effects of ethanol withdrawal. Brain Res. 605, 25-32. doi: 10.1016/0006-8993(93)91352-s

Rawsthorne, H., Calahorro, F., Holden-Dye, L., O' Connor, V., and Dillon, J. (2021). Investigating autism associated genes in C. elegans reveals candidates with a role in social behaviour. PLoS One 16:e0243121. doi: 10.1371/journal. pone. 0243121

Renn, S. C., Park, J. H., Rosbash, M., Hall, J. C., and Taghert, P. H. (1999). A pdf neuropeptide gene mutation and ablation of PDF neurons each cause severe abnormalities of behavioral circadian rhythms in Drosophila. Cell 99, 791-802. doi: 10.1016/s0092-8674(00)81676-1

Ressler, K. J., Mercer, K. B., Bradley, B., Jovanovic, T., Mahan, A., Kerley, K., et al. (2011). Post-traumatic stress disorder is associated with PACAP and the PAC1 receptor. Nature 470, 492-497.

Rex, E., Molitor, S. C., Hapiak, V., Xiao, H., Henderson, M., and Komuniecki, R. (2004). Tyramine receptor (SER-2) isoforms are involved in the regulation of pharyngeal pumping and foraging behavior in Caenorhabditis elegans. J. Neurochem. 91, 1104-1115. doi: 10.1111/j.1471-4159.2004.02787.x

Rogers, C., Reale, V., Kim, K., Chatwin, H., Li, C., Evans, P., et al. (2003). Inhibition of Caenorhabditis elegans social feeding by FMRFamide-related peptide activation of NPR-1. Nat. Neurosci. 6, 1178-1185. doi: 10.1038/nn1140

Rose, J. K., Kaun, K. R., Chen, S. H., and Rankin, C. H. (2003). GLR-1, a nonNMDA glutamate receptor homolog, is critical for long-term memory in Caenorhabditis elegans. J. Neurosci. 23, 9595-9599. doi: 10.1523/JNEUROSCI. 23-29-09595.2003

Rose, J. K., Kaun, K. R., and Rankin, C. H. (2002). A new group-training procedure for habituation demonstrates that presynaptic glutamate release contributes to long-term memory in Caenorhabditis elegans. Learn. Mem. 9, 130-137. doi: $10.1101 / \operatorname{lm} .46802$

Russo, A. F. (2017). Overview of Neuropeptides: awakening the Senses? Headache 57, 37-46. doi: 10.1111/head.13084

Sawin, E. R., Ranganathan, R., and Horvitz, H. R. (2000). C. elegans locomotory rate is modulated by the environment through a dopaminergic pathway and by experience through a serotonergic pathway. Neuron 26, 619-631. doi: 10.1016/ s0896-6273(00)81199-x

Schank, J. R., Ryabinin, A. E., Giardino, W. J., Ciccocioppo, R., and Heilig, M. (2012). Stress-related neuropeptides and addictive behaviors: beyond the usual suspects. Neuron 76, 192-208. doi: 10.1016/j.neuron.2012.09.026

Sgroi, S., Capper-Loup, C., Paganetti, P., and Kaelin-Lang, A. (2016). Enkephalin and dynorphin neuropeptides are differently correlated with locomotor hypersensitivity and levodopa-induced dyskinesia in parkinsonian rats. Exp. Neurol. 280, 80-88. doi: 10.1016/j.expneurol.2016.03.024

Shaw, P. J., Cirelli, C., Greenspan, R. J., and Tononi, G. (2000). Correlates of sleep and waking in Drosophila melanogaster. Science 287, 1834-1837.

Sherlekar, A. L., Janssen, A., Siehr, M. S., Koo, P. K., Caflisch, L., Boggess, M., et al. (2013). The C. elegans male exercises directional control during mating through cholinergic regulation of sex-shared command interneurons. PLoS One 8:e60597. doi: 10.1371/journal.pone.0060597

Sherlekar, A. L., and Lints, R. (2014). Nematode Tango Milonguero - the C. elegans male's search for the hermaphrodite vulva. Semin. Cell Dev. Biol. 33, 34-41. doi: 10.1016/j.semcdb.2014.05.009

Sorensen, A. T., Kanter-Schlifke, I., Lin, E. J., During, M. J., and Kokaia, M. (2008). Activity-dependent volume transmission by transgene NPY attenuates glutamate release and LTP in the subiculum. Mol. Cell. Neurosci. 39, 229-237. doi: 10.1016/j.mcn.2008.06.014

Soria, V., Martinez-Amoros, E., Escaramis, G., Valero, J., Perez-Egea, R., Garcia, C., et al. (2010). Differential association of circadian genes with mood disorders: CRY1 and NPAS2 are associated with unipolar major depression and CLOCK and VIP with bipolar disorder. Neuropsychopharmacology 35, 1279-1289. doi: 10.1038/npp.2009.230

Soto, R., Goetting, D. L., and Van Buskirk, C. (2019). NPR-1 Modulates Plasticity in C. elegans Stress-Induced Sleep. iScience 19, 1037-1047. doi: 10.1016/j.isci. 2019.08.050
Soya, S., and Sakurai, T. (2020). Evolution of Orexin Neuropeptide System: structure and Function. Front. Neurosci. 14:691. doi: 10.3389/fnins.2020.00691

Srinivasan, S. (2020). Neuroendocrine control of lipid metabolism: lessons from C. elegans. J. Neurogenet. 34, 482-488. doi: 10.1080/01677063.2020.1777116

Stawicki, T. M., Takayanagi-Kiya, S., Zhou, K., and Jin, Y. (2013). Neuropeptides function in a homeostatic manner to modulate excitation-inhibition imbalance in C. elegans. PLoS Genet. 9:e1003472. doi: 10.1371/journal.pgen.1003472

Steidl, S., Rose, J. K., and Rankin, C. H. (2003). Stages of memory in the nematode Caenorhabditis elegans. Behav. Cogn. Neurosci. Rev. 2, 3-14. doi: 10.1177/ 1534582303002001001

Steuer Costa, W., Van der Auwera, P., Glock, C., Liewald, J. F., Bach, M., Schuler, C., et al. (2019). A GABAergic and peptidergic sleep neuron as a locomotion stop neuron with compartmentalized Ca2+ dynamics. Nat. Commun. 10:4095. doi: 10.1038/s41467-019-12098-5

Suo, S., Harada, K., Matsuda, S., Kyo, K., Wang, M., Maruyama, K., et al. (2019). Sexually Dimorphic Regulation of Behavioral States by Dopamine in Caenorhabditis elegans. J. Neurosci. 39, 4668-4683. doi: 10.1523/JNEUROSCI. 2985- 18.2019

Suo, S., Kimura, Y., and Van Tol, H. H. (2006). Starvation induces cAMP response element-binding protein-dependent gene expression through octopamine-Gq signaling in Caenorhabditis elegans. J. Neurosci. 26, 10082-10090. doi: 10.1523/ JNEUROSCI.0819-06.2006

Sutcliffe, J. G., and de Lecea, L. (2002). The hypocretins: setting the arousal threshold. Nat. Rev. Neurosci. 3, 339-349. doi: 10.1038/nrn808

Szentirmai, E., and Krueger, J. M. (2006). Central administration of neuropeptide Y induces wakefulness in rats. Am. J. Physiol. Regul. Integr. Comp. Physiol. 291, R473-R480.

Thiele, T. E., Marsh, D. J., Ste Marie, L., Bernstein, I. L., and Palmiter, R. D. (1998). Ethanol consumption and resistance are inversely related to neuropeptide $\mathrm{Y}$ levels. Nature 396, 366-369. doi: 10.1038/24614

Thorsell, A., Repunte-Canonigo, V., O’Dell, L. E., Chen, S. A., King, A. R., Lekic, D., et al. (2007). Viral vector-induced amygdala NPY overexpression reverses increased alcohol intake caused by repeated deprivations in Wistar rats. Brain 130, 1330-1337. doi: 10.1093/brain/awm033

Turek, M., Besseling, J., Spies, J. P., Konig, S., and Bringmann, H. (2016). Sleepactive neuron specification and sleep induction require FLP-11 neuropeptides to systemically induce sleep. Elife 5:e12499. doi: 10.7554/eLife.12499

van den Pol, A. N. (2012). Neuropeptide transmission in brain circuits. Neuron 76, 98-115.

Velazquez-Marrero, C., Burgos, A., Garcia, J. O., Palacio, S., Marrero, H. G., Bernardo, A., et al. (2016). Alcohol Regulates BK Surface Expression via Wnt/beta-Catenin Signaling. J. Neurosci. 36, 10625-10639. doi: 10.1523/ JNEUROSCI.0491-16.2016

Wagenaar, D. A., Hamilton, M. S., Huang, T., Kristan, W. B., and French, K. A. (2010). A hormone-activated central pattern generator for courtship. Curr. Biol. 20, 487-495.

Wang, C., Xin, L., Cai, C. C., Cong, C. Y., Xie, J. F., Kong, X. P., et al. (2020). Neuropeptide S Displays as a Key Neuromodulator in Olfactory Spatial Memory. Chem. Senses 45, 195-202. doi: 10.1093/chemse/bjaa003

Watteyne, J., Peymen, K., Van der Auwera, P., Borghgraef, C., Vandewyer, E., Van Damme, S., et al. (2020). Neuromedin U signaling regulates retrieval of learned salt avoidance in a C. elegans gustatory circuit. Nat. Commun. 11:2076. doi: 10.1038/s41467-020-15964-9

Wen, J. Y., Kumar, N., Morrison, G., Rambaldini, G., Runciman, S., Rousseau, J., et al. (1997). Mutations that prevent associative learning in C. elegans. Behav. Neurosci. 111, 354-368.

White, J. G., Southgate, E., Thomson, J. N., and Brenner, S. (1986). The structure of the nervous system of the nematode Caenorhabditis elegans. Philos. Trans. $R$. Soc. Lond. B Biol. Sci. 314, 1-340.

Wise, R. A. (2004). Dopamine, learning and motivation. Nat. Rev. Neurosci. 5, 483-494. doi: 10.1038/nrn1406

Wong, S. Q., Jones, A., Dodd, S., Grimes, D., Barclay, J. W., Marson, A. G., et al. (2018). A Caenorhabditis elegans assay of seizure-like activity optimised for identifying antiepileptic drugs and their mechanisms of action. J. Neurosci. Methods 309, 132-142. doi: 10.1016/j.jneumeth.2018.09.004

Wu, T., Duan, F., Yang, W., Liu, H., Caballero, A., Fernandes de Abreu, D. A., et al. (2019). Pheromones Modulate Learning by Regulating the Balanced Signals of 
Two Insulin-like Peptides. Neuron 104, 1095-1109.e5. doi: 10.1016/j.neuron. 2019.09.006

Xu, Y. L., Reinscheid, R. K., Huitron-Resendiz, S., Clark, S. D., Wang, Z., Lin, S. H., et al. (2004). Neuropeptide S: a neuropeptide promoting arousal and anxiolytic-like effects. Neuron 43, 487-497. doi: 10.1016/j.neuron.2004. 08.005

Yin, J. A., Gao, G., Liu, X. J., Hao, Z. Q., Li, K., Kang, X. L., et al. (2017). Genetic variation in glia-neuron signalling modulates ageing rate. Nature 551, 198-203. doi: $10.1038 /$ nature24463

Yu, Y., Zhi, L., Guan, X., Wang, D., and Wang, D. (2016). FLP-4 neuropeptide and its receptor in a neuronal circuit regulate preference choice through functions of ASH-2 trithorax complex in Caenorhabditis elegans. Sci. Rep. 6:21485. doi: $10.1038 /$ srep21485

Zhang, L., Yagi, M., and Herzog, H. (2012). The role of NPY and ghrelin in anorexia nervosa. Curr. Pharm. Des. 18, 4766-4778. doi: 10.2174/13816121280321 6988

Zhao, P., Qian, X., Nie, Y., Sun, N., Wang, Z., Wu, J., et al. (2019). Neuropeptide S Ameliorates Cognitive Impairment of APP/PS1 Transgenic Mice by Promoting Synaptic Plasticity and Reducing Abeta Deposition. Front. Behav. Neurosci. 13:138. doi: 10.3389/fnbeh.2019.00138
Zhdanova, I. V., Wang, S. Y., Leclair, O. U., and Danilova, N. P. (2001). Melatonin promotes sleep-like state in zebrafish. Brain Res. 903, 263-268. doi: 10.1016/ s0006-8993(01)02444-1

Conflict of Interest: The authors declare that the research was conducted in the absence of any commercial or financial relationships that could be construed as a potential conflict of interest.

Publisher's Note: All claims expressed in this article are solely those of the authors and do not necessarily represent those of their affiliated organizations, or those of the publisher, the editors and the reviewers. Any product that may be evaluated in this article, or claim that may be made by its manufacturer, is not guaranteed or endorsed by the publisher.

Copyright $\odot 2021$ Bhat, Shahi, Surendran and Babu. This is an open-access article distributed under the terms of the Creative Commons Attribution License (CC BY). The use, distribution or reproduction in other forums is permitted, provided the original author(s) and the copyright owner(s) are credited and that the original publication in this journal is cited, in accordance with accepted academic practice. No use, distribution or reproduction is permitted which does not comply with these terms. 